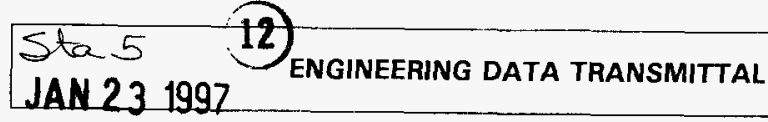

1. EDT $1602: 5$

\begin{tabular}{|l|l|}
\hline $\begin{array}{l}\text { 2. To: (Receiving Organization) } \\
\text { Distribution List }\end{array}$ & $\begin{array}{l}\text { 3. From: (Originating Organization) } \\
\text { PFP Project }\end{array}$ \\
\hline 5. Proj./Prog./Dept./Div.: & 6. Cog. Engr.: \\
W-460 & E. V. Weiss \\
\hline
\end{tabular}

8. Originator Remarks:

See attached HNF-SD-W460-FDC-001, Rev 0, "Plutonium Stabilization and Handling (PuSH) Functional Design Criteria (FDC)." The document was revised per RL comments and is routed for your review and approval.

11. Receiver Remarks:

Original document ID: WHC-SD-CP-FDC-001, Draft Revision 0 (EDT 615767) was not approved by RL. ID will not be used.
4. Related EDT No.:

NA

7. Purchase Order No:

NA

9. Equip./Component No.:

NA

10. System/BIdg./Facility:

PFP

12. Major Assm. Dwg. No.:

NA

13. Permiu/Permit Application No:

NA

14. Required Response Date:

ASAP

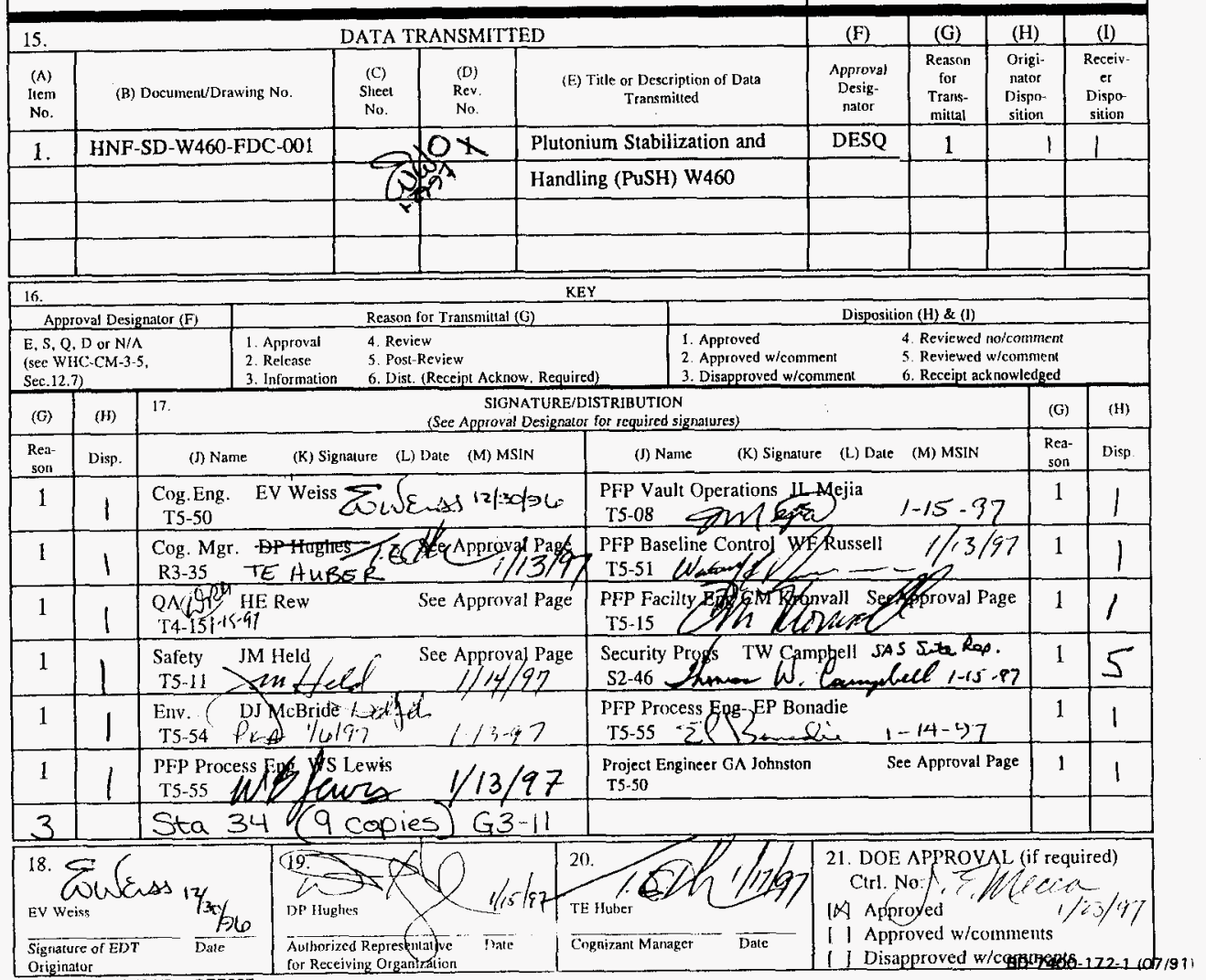

(D)-7400-17?-7 ranA) GEF097 


\title{
Plutonium Stabilization and Handling (PuSH)
}

\author{
Evelyn V. Weiss
}

Fluor Daniel Hanford Company, Richland, WA 99352

U.S. Department of Energy Contract DE-AC06-96RL13200

EDT/ECN: 160215

UC: UC-721

Org Code: $15 \mathrm{COO}$

Charge Code: K6182

B\&R Code: EW7003000

Total Pages: $76-73$

Key Words: Plutonium, PFP, Stabilization, Handling, SNM, FDC, PuSH, PuSAP, W460, Storage, Vault, 94-1, SPS

Abstract: This Functional Design Criteria (FDC) addresses construction of a Stabilization and Packaging System (SPS) to oxidize and package for long term storage remaining plutonium-bearing special nuclear materials currently in inventory at the Plutonium Finishing Plant (PFP), and modification of vault equipment to allow storage of resulting packages of stabilized SNM for up to fifty years. The major sections of the project are: site preparation; SPS Procurement, Installation, and Testing; storage vault modification; and characterization equipment additions.

The SPS will be procured as part of a Department of Energy nationwide common procurement. Specific design criteria for the SPS have been extracted from that contract and are contained in an appendix to this document.

TRADEMARK DISCLAIMER. Reference herein to any specific commercial product, process, or service by trade name. trademark, manufacturer, or otherwise, does not necessarily constitute or imply its endorsement, recommendation, or favoring by the United States Government or any agency thereof or its contractors or subcontractors.

Printed in the United States of America. To obtain copies of this document, contact: WHC/BCS Document Control Services, P. O. Box 1970, Mailstop H6-08, Richland WA 99352, Phone (509) 372-2420; Fax (509) 376-4989.
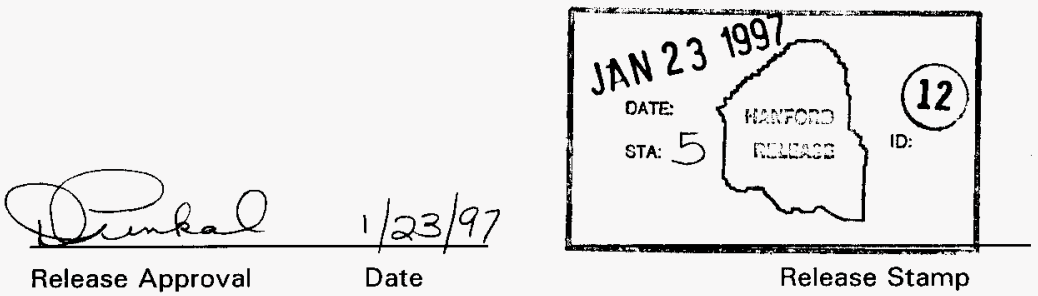

\section{Approved for Public Release}




\section{FUNCTIONAL DESIGN CRITERIA PLUTONIUM STABILIZATION AND HANDLING (PUSH), PROJECT W-460}

Issued by:

\section{FLUOR DANIEL HANFORD COMPANY}

under Contract DE-AC06-96RL13200

December 1996

for the

\section{U.S. DEPARTMENT OF ENERGY RICHLAND OPERATIONS OFFICE RICHLAND, WASHINGTON}

REVISED BY:

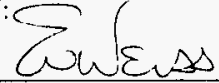

Evelyn V. Weiss, PFP Transition Engineering

$\frac{12 \cdot 30-9) 60}{\text { Date }}$

APPROVALS:

D.A. $\ln 6$

G. A. Jo/nnston, FDNW Project Engineer

$\frac{1-13-97}{\text { Date }}$

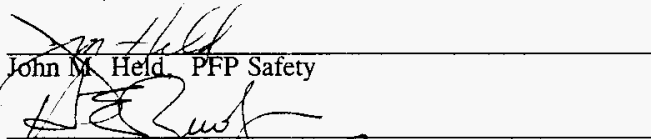

Howate. Beyy, Jr. PEP zurality Assurance
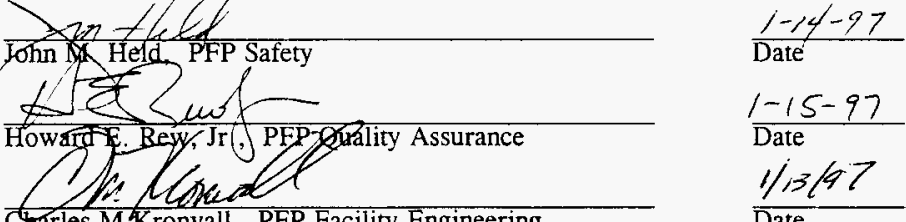

Charles M.Kronvall, PFP Facility Engineering
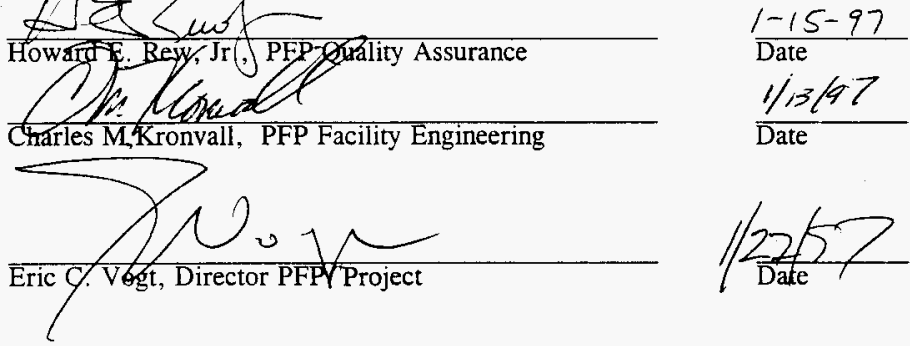

DEPARTMENT OF ENERGY APPROVAL:

SUT

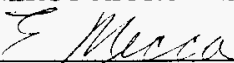

U.S. Department of Energy, Richland Operations Office

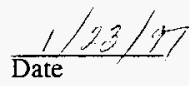


This page left intentionally blank. 


\title{
PLUTONIUM STABILIZATION AND HANDLING (PuSH) FUNCTIONAL DESIGN CRITERIA
}

\author{
TABLE OF CONTENTS
}

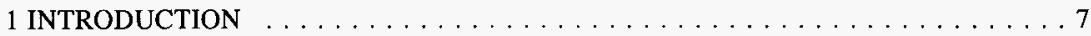

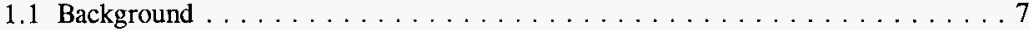

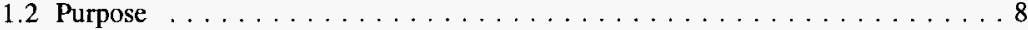

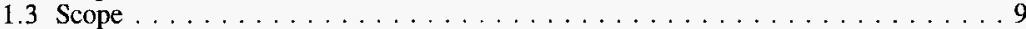

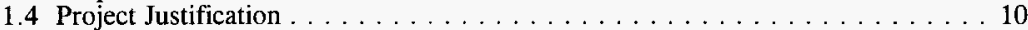

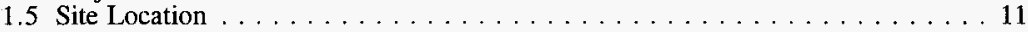

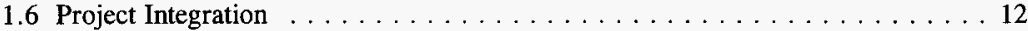

1.7 Prototype Stabilization and Packaging System Process Description . . . . . . . 13

2 PROJECT PERFORMANCE CRITERIA $\ldots \ldots \ldots \ldots \ldots \ldots \ldots \ldots \ldots$

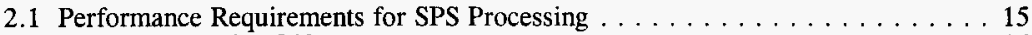

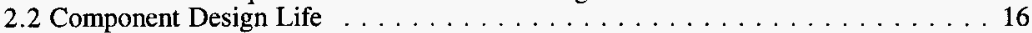

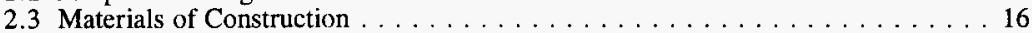

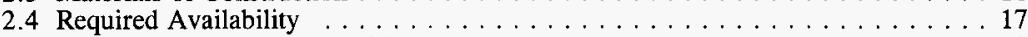

2.5 Operability and Maintainability $\ldots \ldots \ldots \ldots \ldots \ldots \ldots \ldots \ldots \ldots \ldots \ldots \ldots \ldots \ldots$

3 PROCESS AND STORAGE CRITERIA . . . . . . . . . . . . . . . . . . 19

3.1 SPS Support System Process Criteria $\ldots \ldots \ldots \ldots \ldots \ldots \ldots \ldots \ldots \ldots \ldots \ldots$

3.1 .1 Utility Interfaces for SPS $\ldots \ldots \ldots \ldots \ldots$

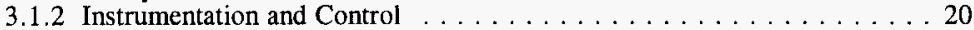

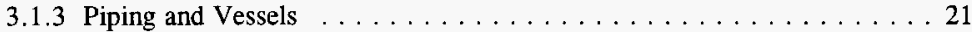

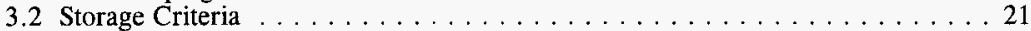

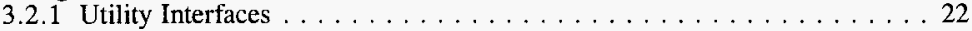

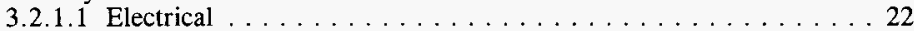

3.2.1.2 Ventilation and Air Conditioning $\ldots \ldots \ldots \ldots \ldots \ldots \ldots \ldots \ldots \ldots$

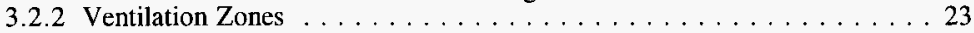

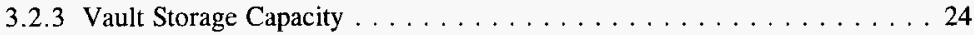

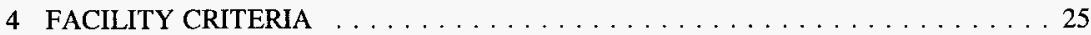

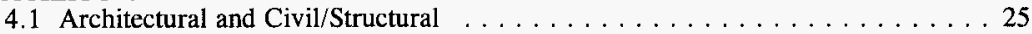

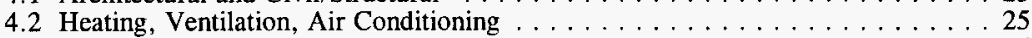

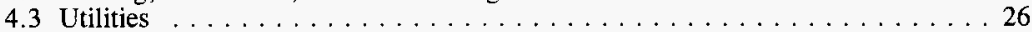

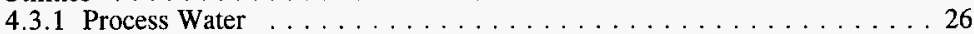

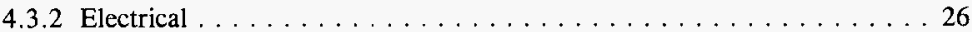

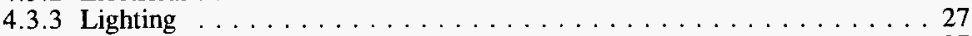

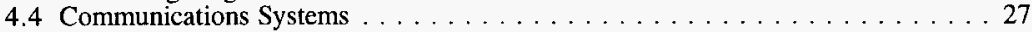

4.5 Automatic Data Processing . . . . . . . . . . . . . . . . . 27

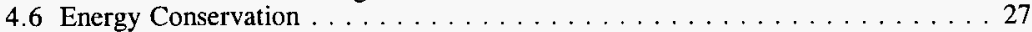

4.7 Maintenance . . . . . . . . . . . . . . . . . . . 27

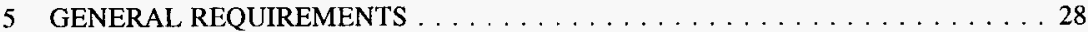

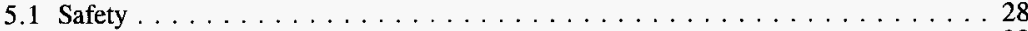

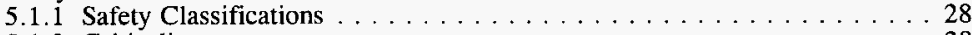

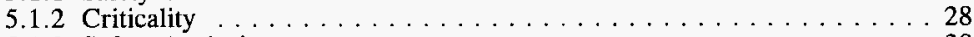

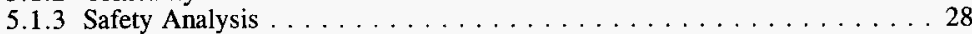

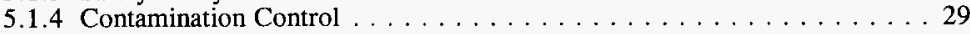


5.1 .5 Radiation Exposure . . . . . . . . . . . . . . . . . . . . 29

5.1.5.1 Radiation Exposure During Maintenance and Decontamination . . 30

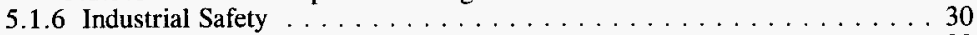

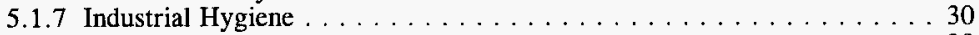

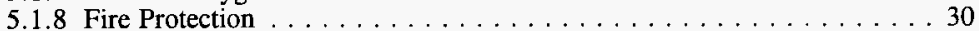

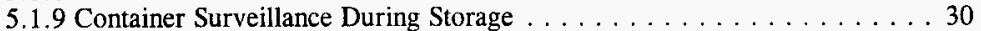

5.2 Environmental Protection and Compliance . . . . . . . . . . . . . 31

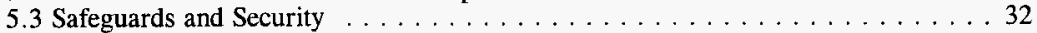

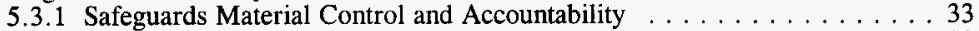

5.3 .1 .1 SPS Unit . . . . . . . . . . . . . . . . . 33

5.3.1.2 Plutonium Storage Vault . . . . . . . . . . . . . 33

5.3 .2 Interface with International Atomic Energy Agency . . . . . . . . . 34

5.4 Natural Forces . . . . . . . . . . . . . . . . . . . . . . . . 34

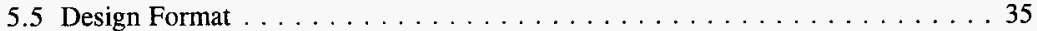

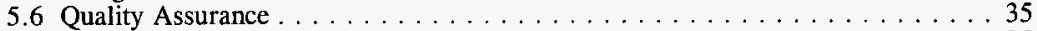

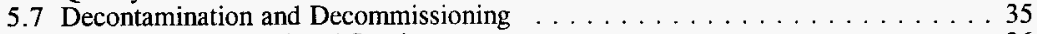

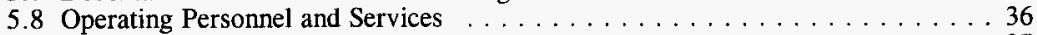

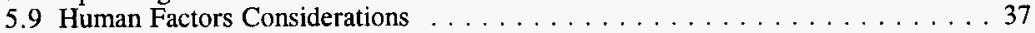

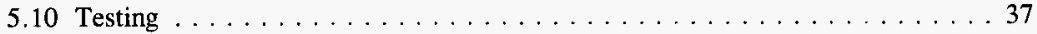

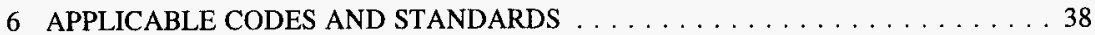

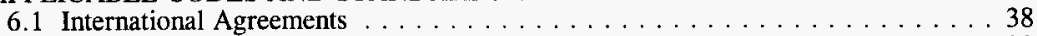

6.2 Federal Rules and Guidelines . . . . . . . . . . . . . . . . . 38

6.3 Department of Energy National Orders, Contracts and Guidelines . . . . . . . . . 39

6.4 National Consensus Standards . . . . . . . . . . . . . . . . . . . . 39

6.5 Washington State Regulations . . . . . . . . . . . . . . . . . 40

6.6 Hanford Implementing Directives and Manuals . . . . . . . . . . . . . . 40

6.7 Technical Documents . . . . . . . . . . . . . . . . . . . . . 41

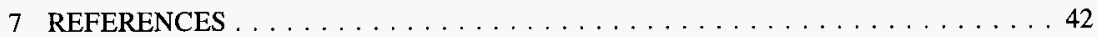

8 SELECTED ACRONYMS AND ABBREVIATIONS $\ldots \ldots \ldots \ldots \ldots$

APPENDIX A Background Information about $2736-Z$ Complex Ventilation $\ldots \ldots \ldots$

APPENDIX B PERFORMANCE SPECIFICATIONS FOR STABILIZATION AND

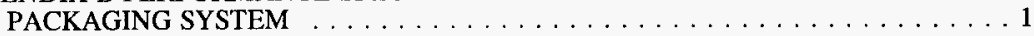

A Performance Characteristics $\ldots \ldots \ldots \ldots \ldots \ldots \ldots \ldots \ldots \ldots$

A.1 Stabilization and Packaging System Performance . . . . . . . . . . 1

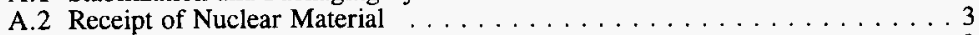

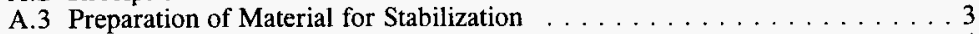

A.4 Transport of Containers within the Glovebox System . . . . . . . . . . . . 4

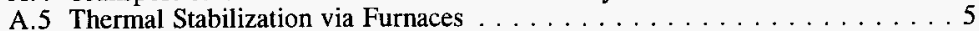

A.6 Testing of Stabilized Materials for Moisture / Volatiles Content . . . . . . . 6

B Specialty Component Specifications $\ldots \ldots \ldots \ldots \ldots \ldots \ldots$

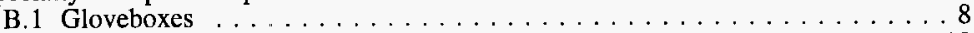

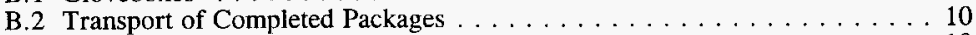

B.3 Furnace Trays . . . . . . . . . . . . . . . . . . 10 


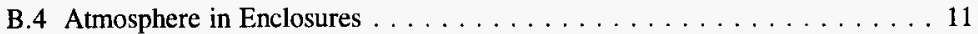

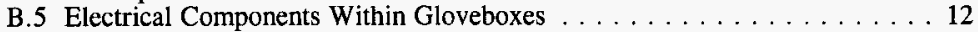

B.6 Seismic Considerations for Support Structures and Platforms . . . . . . 12

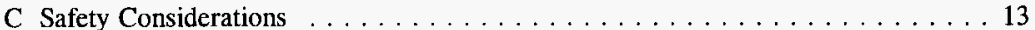

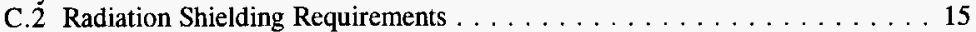

C.3 Design for Nuclear Safety $\ldots \ldots \ldots \ldots \ldots \ldots \ldots \ldots \ldots \ldots$

D SPS Process Control and Data Management $\ldots \ldots \ldots \ldots \ldots \ldots$

D.1 Process Control System . . . . . . . . . . . . . . . . 16

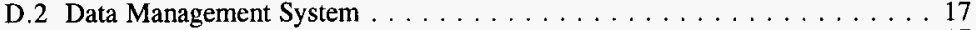

D.3 Control and Data System Security $\ldots \ldots \ldots \ldots \ldots \ldots \ldots \ldots$

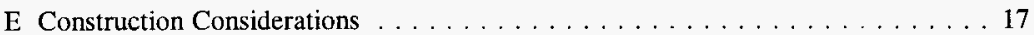

E.1 Site Construction Constraints $\ldots \ldots \ldots \ldots \ldots \ldots \ldots \ldots \ldots$

E.2 Protective Coatings and Cleaning $\ldots \ldots \ldots \ldots \ldots \ldots \ldots \ldots \ldots$

E. 3 System Quality Factors $\ldots \ldots \ldots \ldots \ldots \ldots \ldots \ldots \ldots \ldots$

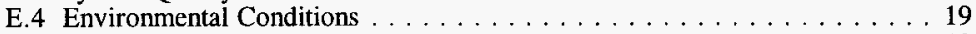

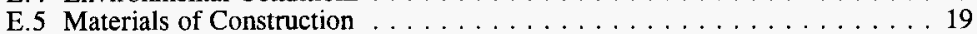

E.6 Toxic Products and Formulations $\ldots \ldots \ldots \ldots \ldots \ldots \ldots$

E.7 Use of Standard and Commercial Parts $\ldots \ldots \ldots \ldots \ldots \ldots \ldots$

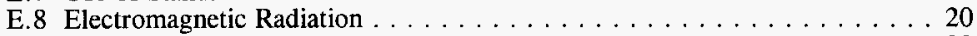

E.9 Nameplates and Product Marking $\ldots \ldots \ldots \ldots \ldots \ldots \ldots \ldots \ldots \ldots \ldots \ldots \ldots \ldots$

E.10 Construction for Ease of Decontamination $\ldots \ldots \ldots \ldots \ldots \ldots \ldots 21$

E.11 Human Factors Engineering $\ldots \ldots \ldots \ldots \ldots \ldots \ldots \ldots \ldots \ldots \ldots \ldots$

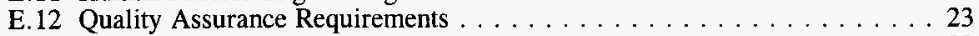

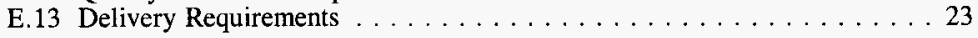


This page left intentionally blank. 


\section{INTRODUCTION}

Section 1 provides background information that may be useful to the execution of Project W-460, but is not part of the functional criteria for the project. Criteria contained in Sections 2 through 5 constitute the technical and functional requirements for design of project elements.

\subsection{Background}

The Hanford Site near Richland, Washington, has completed its production mission and is now executing its new mission of environmental restoration. Part of the new mission is to stabilize and suitably store or dispose of all remaining plutonium-bearing special nuclear materials (SNM) at the Site. Remaining inventories of SNM at the Hanford Site are housed in the PFP Complex, a facility which formerly produced plutonium in metal shapes and oxide powder for defense purposes. Much of the SNM inventory at the PFP is of solid form, consisting of plutonium oxides or plutonium/uranium oxides of varying degrees of purity, stored in sealed packages in secure vault storage.

The Defense Nuclear Facilities Safety Board (DNFSB) was chartered by the United States Congress to oversee safety related issues. The DNFSB generated Recommendation 94-1, dated May 26, 1994, which calls for plutonium SNM stabilization and storage actions to be expedited. As part of response commitments, the DOE chartered the Nuclear Materials Stabilization Task Group (NMSTG) to manage the multiple tasks required to have all remaining fissile materials at DOE sites in safe storage by May 2002 .

The NMSTG has formed several task teams of technical staff from all affected DOE sites; each task team is charged with solving a specific technical problem associated with this effort. One team compiled DOE Standard DOE-STD-3013-94, which contains technical guidelines for the stabilization and packaging of SNM containing greater than 50 percent by weight plutonium to be placed in long term interim storage. The specific stabilization parameters and packaging configurations discussed in the Standard have been a subject of much technical discussion; a major revision of the Standard (DOE-STD-3013-96) was recently issued to address key changes determined necessary by users. This document will refer to the 1996 revision of the Standard as "3013" for brevity.

The Plutonium Stabilization and Packaging (PuSAP) task team was chartered to implement 3013 via a common DOE procurement of stabilization and packaging equipment as well as the packaging materials themselves. The PuSAP task team is led by staff from NMSTG with members from the Rocky Flats Environmental Test Site (RFETS), the Savannah River Site (SRS), the Los Alamos National Laboratory (LANL), Lawrence Livermore National Laboratory (LLNL) and the Hanford Site (RL). The DOE Oakland Office (OAK) is acting as the contracting office for the procurement. Using a consensus approach, the team established requirements for a Stabilization and Packaging System (SPS). Procurement documents were issued via OAK, and a contract was awarded (DOE Contract DE-AC03-96SF20948, more commonly the PuSAP contract) to a team 
headed by British Nuclear Fuels Limited and Raytheon Engineers and Constructors. The contract includes design, construction and installation of a prototype unit to be installed in Building 707 at RFETS plus very similar SPS units for Rocky Flats Building 371, Savannah River and Hanford plus initial procurement of package components.

\subsection{Purpose}

Although Hanford's Plutonium Finishing Plant (PFP) has an active program for stabilizing remaining inventories of SNM, the Site does not presently have the capability to package stabilized SNM into the welded containers called for by 3013 . In addition, these containers are larger than those currently in use at the PFP, and will not physically fit into the storage fixtures in secure vault storage at the PFP.

Project W-460, Plutonium Stabilization and Handling (PuSH), encompasses several related actions which will implement the provisions of 3013 for SNM inventories of plutonium and plutonium/uranium oxides at the PFP, and will comply with the commitments of DNFSB 94-1 to stabilize and package remaining SNM by May 2002. The "3013 packages" will be placed in safe secure storage for up to fifty years.

The Project will consolidate stabilization, packaging and storage functions into a single location within the PFP facility, the $2736-\mathrm{Z}$ Complex. This will allow eventual deactivation of other PFP facility areas no longer needed while maintaining all functions required for safe storage.

Space will be made for the SPS unit within Building 2736-ZB via rearrangement of functions within the building and the addition of some office space external to the permanent buildings. One SPS unit will be procured and installed in conjunction with the national DOE contract mentioned above. Storage fixtures and associated equipment will be modified to accommodate the number of 3013 packages needed to accommodate existing PFP inventory in the storage vault building, 2736-Z. Nondestructive assay (NDA) capability will be updated to accommodate the physical size and bulk of the 3013 packages plus anticipated requirements of contents radiography. The Project will upgrade utilities and support services to allow safe operation of the SPS and the storage vaults.

Storage of a portion of the PFP SNM inventory is maintained under an agreement between the United States and the IAEA per IAEA Information Circular/288. Modifications to packaging and storage conditions for these materials will require further agreement between the United States and the IAEA and continued compliance with Safeguards Criteria, T.S.-N0.\#3, 1994-04-15. The outcome of negotiations being prepared in a parallel effort to this project will affect equipment design in the storage vaults. It is anticipated that this material must continue to be kept physically separated from the rest of the PFP SNM inventory. 


\subsection{Scope}

Project W-460 is arranged into four major tasks:

\section{- Site Preparation}

A site selection study (see Section 1.5) chose Rooms 641 and 642 in Building 2736-ZB to house the SPS. The rooms will be combined into one, with a small control room located in an adjacent area of the building. Structural preparations such as temporary large equipment access will be made. Various facility work areas will be relocated, with some non structural modifications, to allow all needed tasks to be carried out.

Capacities of facility ventilation systems will be verified and enhanced if necessary. Configuration of the systems will be modified if necessary to provide appropriate separation of facility and process enclosure ventilation. The capacity of utilities and support systems required for operation of the SPS and of the modified vaults will be verified; for existing utilities such as electrical power, reconfiguration or enhancement may be required. Utilities not currently available or of insufficient capacity at 2736-ZB such as nitrogen gas, bottled laser gases or dry air will be supplied by this project.

- SPS Procurement. Installation and Testing

Via the common procurement agent (DOE-OAK), the design of the prototype SPS unit (to be tested at Rocky Flats during 1997) will be modified to suit Hanford's needs, constructed, installed and tested. It is anticipated that the vendor will install the SPS equipment. The system design may utilize surplus equipment currently at the Hanford Site if feasible, e.g. a glovebox for size reduction of impure oxide forms.

Within the SPS, items to be procured will include approximately thirteen gloveboxes and fume hoods with associated ventilation and service connections, stabilization and laboratory furnaces (a total of three are anticipated), a laser welding machine with multiple waveguides, a variety of automated material movement equipment and a system control unit. An initial order of packaging components will be procured for equipment testing and qualification.

Technical requirements for this phase of the Project are detailed in Appendix B and governed by the PuSAP contract. The Hanford portion of the contract is managed by a Contracting Officer's Representative (COR) appointed by the Project Management Division of RL (see Section 1.6).

- Vault Modification

Secure vault storage fixtures in Building $2736-\mathrm{Z}$ will be modified to accommodate the 3013 packages sealed in the SPS. A minimum of two vault rooms must have fixtures modified to hold the existing inventory, as the portion of the PFP inventory under agreement with the IAEA must be maintained physically separate from the rest of the inventory. The storage configuration will be determined based on requirements of domestic and international 
security. Security equipment and data management configuration (seals, item identification equipment, database connections, etc) will be also modified as needed.

Significant operational sequencing will be required to allow construction access while minimizing radiological dose to construction and operational workers and maintaining required physical security. Consolidation of the inventory now in vault storage to allow an empty room prior to construction of new vault storage fixtures will require advance planning and creativity. Any temporary storage modifications will be designed, installed and removed by this project.

- Control and Laboratory Equipment Additions

Surveillance equipment and international safeguards equipment currently in Room 642 will be relocated within Building 2736-ZB to make space for the SPS unit.

Laboratory equipment for non-destructive assay (NDA) of 3013 packages will be purchased and installed in the 2736-ZB NDA laboratory, Room 637. One to three (based on planned SPS throughput rates) calorimetry units will be purchased to accommodate the new package configuration, along with a pre-equilibration bath if deemed necessary. The gamma scan unit will be updated, and a second unit will be purchased if required to handle SPS throughput rates. Based on discussions with the PuSAP task team, space for a radiography unit capable of determining weld signatures and contents baselining will be set aside as a good practice item. Site preparation for these items will be undertaken in sequence to minimize disruptions to NDA laboratory operations.

\subsection{Project Justification}

Storage of plutonium SNM (oxides or metals of greater than fifty percent by weight plutonium) in a common package intended to maintain containment for 50 years is one of the key elements of the DOE program to stabilize nonreactor nuclear facilities across the United States. This key element is embodied in DOE Standard DOE-STD-3013-96. Although DOE standards are guidelines rather than compliance documents, the NMSTG has directed compliance with its provisions via the PuSAP contract.

The DOE has chosen to coordinate procurement of similar stabilization and packaging equipment for DOE sites containing significant quantities of SNM to assure that all containers of plutonium SNM to be stored for future disposition will have common outer dimensions and markings. Through the PuSAP contract, a prototype design has been established for four SPS units: the prototype and a second unit to be installed at RFETS, one unit at SRS and one unit at Hanford.

It is necessary to change vault storage fixture configuration because the packaging configuration described in 3013 is larger than those currently used for plutonium storage at the 
PFP. Packages will not fit into current monitored storage pedestals in PFP vaults. In addition, the package has more robust walls and hence will tolerate a much higher internal pressure than existing Hanford storage packaging, making various existing safety and security equipment less than useful. The project will focus on an approach which modifies existing storage areas within PFP secure vaults rather than constructing an entire new facility to accommodate the 3013 packaging design. Care must be taken to simultaneously satisfy safety considerations along with both domestic and international security requirements.

A dose estimate (Vogt, 1996) prepared for PFP management has shown that worker radiological exposure will require careful management to remain within current occupational guidelines and meet facility environmental, safety and health (ESH) objectives during the stabilization and packaging work remaining at the PFP. In order to minimize manual handling of SNM, automation of as much of the stabilization and packaging function as feasible is needed. Tools and automated approaches will be considered to minimize worker dose during transport and handling of 3013 packages. To minimize exposure during local transport within the PFP, the SPS unit should be located within the same Material Access Area as current and planned SNM storage locations.

Current international safeguards requirements for PFP storage vaults include: examination of records and reports, annual physical inventory verifications (PIV), monthly interim inspections, and investigations of storage anomalies as they appear. Of these the PIV is the most significant, both financially and from a personnel radiation exposure perspective. The PIV normally include hands-on inspection and opening of containers for destructive assay (DA), with subsequent repackaging, plus significant hands-on work to provide NDA. There is a strong desire to minimize reopening of plutonium storage packages once stabilized and packaged to meet 3013 . In order to minimize DA and the hands-on work of inspection and NDA, enhanced security measures are required to satisfy international and domestic safeguard requirements. There is clear benefit to reducing the cost and worker risk associated with the application of domestic and international safeguards.

Additionally, there is significant world-wide experience of relatively frequent safeguards instrumentation failure. The strong desirability of minimizing intrusive safeguards inspections once the 3013 packages are implemented and the low marginal cost of proceeding with redundant safeguards instrumentation justifies adoption of an additional layer of containment and surveillance design criteria to assure that adequate protection is maintained continuously (see Section 5.3.2).

\subsection{Site Location}

The SPS will be installed at the PFP facility in the 200 West area of the Hanford Site approximately 30 miles northwest of Richland, Washington. The specific location identified for the SPS is rooms 641 and 642 of the 2736-ZB building within the PFP Protected Area. Installation will not disturb virgin ground. 
Several facility modifications to Building $2736-\mathrm{ZB}$ and the connected storage vault, Building 2736-Z, will be required in order to install the required stabilization and packaging system within 2736-ZB and to modify the vault areas to accommodate the configuration of the 3013 package.

The processing system requires a significant amount of floor space because of fixture separation mandated by criticality safety considerations. The following specific site factors, as specified in WHC-SD-CP-TI-202, "Location Assessment for the Plutonium Stabilization and Handling Process, " were considered in locating the SPS unit:

- Minimization of worker radiation exposure during processing resulting from background radiation levels and manual operations to as low as reasonably achievable (ALARA),

- criticality safety,

- security and safeguards,

- cost and ease of installation of the SPS,

- minimizing of worker radiation exposure and manpower for transport of SNM to and from secure storage vaults, and

- availability of plant services.

\subsection{Project Integration}

Integration of this project into national and Hanford activities will require a significant effort. Primary programmatic interfaces are briefly discussed below:

This project shall be coordinated with the common procurement activities of DOE Contract DE-AC03-96SF20948 via the RL COR in coordination with the NMSTG and DOE-OAK. A Project Management Plan will delineate responsibilities and interface points.

Resources and activities for this project be coordinated with other PFP stabilization and deactivation activities as planned by the Hanford Site Integrated Stabilization Management Plan (SISMP), WHC-EP-0853, a planning document generated to coordinate PFP activities which lead towards completion of the May 2002 deadline for stabilization and placement in safe storage of remaining plutonium at Hanford. The project shall minimize interference with the completion of other 94-1 PFP stabilization and deactivation activities or safe maintenance of the PFP facility.

This project will also be coordinated with several capital projects at Hanford. The most important ones are: C-189 "PFP Standby Diesel Generator Upgrades" and W-420 "Stack Monitoring Upgrades." 
In addition to the usual domestic security considerations, international security shall be considered for all aspects of this project via DOE contact with the IAEA. It is anticipated that some equipment for monitoring of secure vault storage operations will be required.

Some reconfiguration of laboratory space, existing vault monitoring equipment and other functions within building 2736-ZB will required for installation and operation of the SPS and support equipment. Additional office space will be required for the duration of SPS operation to stabilize and package the PFP inventory. Existing personnel change room facilities are anticipated to be adequate. No personnel services are provided by this project. Personnel services within the PFP complex are available to personnel working on this system. SPS unit operation scenarios will be determined during the conceptual design.

\subsection{Prototype Stabilization and Packaging System Process Description}

The PuSAP contract governs the actual design of the SPS unit. The unit is based partially on a similar operation at the British Nuclear Fuels Thorp Plant, Sellafield, England. The initial design of the prototype unit to be installed in RFETS Building 707 is described below for informational purposes only; refer to Appendix B for functional criteria for the Hanford SPS unit. The prototype unit is now in detail design and fabrication, with delivery at RFETS scheduled for March 1997.

The prototype SPS unit will consist of two major modules: stabilization and packaging. The stabilization module will consist of a Receipt Hood and conveyor connection to the 707 conveyor system, a Material Preparation Area, Transport Area, Furnace Area and a Test Area with a LossOn-Ignition furnace. The packaging module will consist of a Can Dispense and Fill Area, Can Weigh and Cap Insertion Area, Intermediate Can Handling Area, and Outer Can Weld Monitoring Area.

The design of the prototype's Receipt Hood provides a protected work area for initial receipt of incoming containers. Container identifiers are recorded and the outer container is opened manually. The inner container is removed and transferred thru the entry airlock to the Material Preparation Glovebox (outer container goes to low level waste). In the Material Preparation Glovebox the inner container is assayed, opened, decontaminated, compacted, and loaded out to metal waste. At the Powder Dispensing Station the inner container plutonium oxide is transferred to a batch furnace tray using a screened funnel, screw conveyor, bin vibrator, and tray funnel cover. A Metal Brushing Station is included in the prototype. At the Metal Brushing Station, Pu metals are removed from their inner containers, the loose oxides are brushed off, and the metals are placed in a convenience can. The brushed oxides are returned via a convenience can to the Powder Dispensing Station while the metal is passed on to the packaging area. It is anticipated that the Hanford unit will have a receipt glovebox rather than a fume hood to meet site requirements for plutonium handling; a metal brushing station will not be required as no metal shapes will be handled in the SPS. Recent stabilization experience suggests than size reduction equipment may be required due to agglomeration of particles during heating. 
The Transport Area glovebox contains a conveyor to transport convenience cans of Pu metal and furnace trays between the Material Preparation Area, the Furnace Area, the LOI Test Area, and the Tipping/Dispense/Fill Area. The Furnace Area glovebox contains the furnace glovebox and two Stabilization Furnaces for thermal stabilization of plutonium oxide. The Test Area glovebox contains the LOI Sampling Station, the Sample Desiccator, and the LOI Furnace to verify that $\mathrm{Pu}$ oxide processed thru the stabilization furnaces has achieved acceptable moisture reduction (Loss on Ignition or LOI) test value. In the Dispense and Fill Area, batches of Pu oxides in furnace trays are dispensed into convenience cans, and filled convenience cans (of oxide or metal) are moved to the Can Weigh and Cap Insertion Area. The Dispense and Fill Area contains the Tipping Glovebox, the Dispense/Fill Glovebox, the Seismic Displacement Absorber, the Furnace Tray Elevator/Transpose Unit, the Furnace Tray Tipper, the Convenience Can Transfer Unit, and the Convenience Can Handler.

In the Can Weigh and Cap Insertion Area, a convenience can is loaded into an intermediate can and a can lid blank (cap or bung)is placed in the top. The Can Weigh and Cap Insertion Area includes the Can Weigh and Cap Insertion Glovebox, a Gaslock, a Convenience Can Turntable, the Weigh Scale and Bar Code Reader, the Convenience Can Pusher, the Intermediate Cap Magazine, and the Material Transfer Port. In the Intermediate Can Handling Area, the bung is welded to the intermediate can and the waste is cut off. The Intermediate Can Handling Area includes the Fume Cabinet, the Intermediate Can Rotating Sphincter Seal, the Intermediate Can Storage Magazine, the Laser Welding/Cutting Tool with one waveguide, the Laser Generator, and the Intermediate Can Handling Unit.

In the Outer Can Weld and Monitoring Area, the intermediate can assembly is checked for surface contamination and leaks in the can seal. As each can passes the test, it is loaded into an outer can. A can lid blank (cap or bung) is inserted in the top and the outer can is welded. The whole unit is then leak tested. The Outer Can Weld and Monitoring Area includes the Can Turntable/Trolley, the Outer Can Handling Unit, the Intermediate Can Leak Detection Unit, the Helium Fill/Lid Fitment Unit, the Laser Welder with a second separate waveguide, the Outer Can Contamination Check Unit, and the Outer Can Leak Detection Unit. The Lag Storage Trolley is a shielded and critically safe transfer cart used to transfer storage containers out of the SPS area to the NDA Laboratory or secure storage vault. 


\section{PROJECT PERFORMANCE CRITERIA}

Specific design requirements for the Hanford SPS unit will be designated by the PuSAP contract as noted in Section 1, and carried out by the designated contractor. All other design required for the project, including design of interfaces between the SPS and the facility, is the responsibility of this project.

\subsection{Performance Requirements for SPS Processing}

SPS design requirements are listed in Appendix B; key items are summarized below:

Plutonium-bearing solids containing greater than 50 weight-percent plutonium and uranium will be processed in a system designed to reduce the material to an oxide form and to remove all volatiles and moisture in preparation for safe, interim 50 year storage. The system design must:

- maintain a stabilization process throughput rate of at least two (2) 3013 packages per 8 hour shift, 24 hours a day, 5 days a week;

- $\quad$ minimize waste generation during operation and maintenance;

- provide radiological containment and radiation shielding to maintain annual personnel exposures at $500 \mathrm{mrem}$ or less due to operation of the SPS;

- provide capability to receive and unload all existing containers of solid SNM stored in PFP vaults;

- meet nuclear material control and accountability requirements;

- prepare plutonium for stabilization, and process waste streams for disposal/storage;

- perform thermal stabilization of impure plutonium oxide containing varying amounts of other materials;

- handle closed containers of varying sizes to be repackaged only;

- $\quad$ perform packaging of stabilized materials;

- provide rework capability, including opening of welded containers; and

- provide shielded transport of sealed 3013 packages from the SPS unit to the NDA Laboratory or storage vaults in the $2736-Z$ Complex.

Note that although the prototype SPS unit has the capability for brushing of loose oxides from plutonium metals to be packaged for storage, this capability is not desired for the Hanford SPS unit. No metal items will be stabilized or packaged in the Hanford unit.

Provisions for size reduction and manual handling of materials is required to ensure materials are of a size small enough for initial thorough stabilization processing, to assist further processing of oxides after removal from the furnaces, and to facilitate packaging. This capability is not included in the prototype SPS unit, and provision of size reduction equipment will be an interface responsibility of this project. 
Incoming materials will be held in a variety of container configurations and sizes to be provided to the SPS contractor. The SPS must be capable of receipt of the majority of existing storage packages via sphincter, with provision of an alternate receipt mechanism for unusual packages. As the PFP is actively stabilizing SNM prior to installation of the Hanford SPS unit and is packaging those materials in alternate convenience cans, the unit must be capable of movement of alternate convenience cans directly to the packaging area.

Components and systems which interface with the SPS must provide performance at the level specified for the SPS.

DOE safeguards requirements, IAEA surveillance compatibility requirements, backup power

supply requirements, and safety code requirements for the vaults must be met as specified in various sections of this document.

As feasible, there shall be no permanently installed active equipment elements within the storage vault rooms. Passive elements are acceptable, provided no maintenance is required. Active elements include electrically powered sensors and equipment, equipment with moving parts, and similar equipment. This requirement is imposed to allow operation of the vaults without entry for maintenance. Repair and replacement of active elements shall be possible from outside the vault rooms (IE., from the corridor).

\subsection{Component Design Life}

Design life requirements are broken into two areas: stabilization/packaging equipment and storage vault components. The PuSAP contract requires capability for initial full service usage for seven (7) years after startup, with periodic low volume operation required for 7 to 50 years; interface equipment shall also meet this requirement. After the PFP inventory is in stored in 3013 packages, it is anticipated that the SPS unit will be needed to operate for a brief campaign once a year to accommodate safeguards requirements.

Storage vault component design life will vary according to specific need, with structures and passive storage fixtures and equipment having a minimum 50-year required life. Mechanical and electrical components shall be designed for a minimum 20-year design life with replacement anticipated.

\subsection{Materials of Construction}

Materials of construction and equipment used in this project shall be compatible with the radiological and chemical environment to which they will be exposed for the specified design life of that component. 
In several areas of the SPS, equipment and packaging materials will be exposed to high temperatures (up to $1200 \mathrm{C}\left[2192^{\circ} \mathrm{F}\right]$ ) and frequent thermal cycling. These materials shall be chosen for strength and dimensional stability at high temperature, resistance to corrosion, and high resistance to thermal stress cracking.

Process hardware located inside SPS gloveboxes shall be fabricated of Type 300 series stainless steel, or a similar stainless steel with high temperature properties. Commercial stainless steel hardware may be used outside the glovebox.

Gasket materials for equipment shall be chosen as needed for low permeation, compatibility with low humidity, argon, and oil resistance if necessary.

In PFP storage vault areas, materials will be subjected to temperatures ranging approximately from $16 \mathrm{C}\left(60^{\circ} \mathrm{F}\right)$ up to $260 \mathrm{C}\left(500^{\circ} \mathrm{F}\right)$, with continuous elevated temperatures in the region nearest the storage fixtures. It is known that the 3013 package will provide a different heat transfer parameters than existing packages, however no model is yet available. A basis for more accurate prediction of long term temperature variations within the storage vaults will be determined via thermal analysis of a 3013 package model during conceptual design for this project. Materials used in vault modifications shall be chosen for strength and dimensional stability under conditions of both long term elevated temperatures and occasional wide temperature variation (such as removal from a vault fixture at the high temperature limit to an occupied space).

Normal ambient humidity variations for the Hanford area are anticipated, in addition to mild pressure variations (less than 10 in-wg) due to active ventilation changes.

Components contacting packaging elements shall be compatible with Type 316 stainless steel.

\subsection{Required Availability}

The equipment used for stabilization and packaging shall be capable of operating continuously 24 hours per day, 5 days per week for 7 years and then intermittently for the following 50 years (see section 2.2). Support utilities shall be capable of operating for the same durations.

Facility support systems (ie., ventilation, fire suppression, alarm functions and power) shall be capable of operating continuously 7 days per week, 24 hours per day, for 50 years. Redundant equipment shall be supplied to ensure continuous operation of certain vault safety and security equipment. Critical systems such as exhaust ventilation systems for contamination control and heat removal, safeguards and security monitors and criticality alarms shall have backup power available at all times. Design of critical systems shall be such that minimal scheduled maintenance outages are required. 


\subsection{Operability and Maintainability}

Installation of SPS interfaces, NDA Laboratory equipment, vault storage components and relocation of existing facility functions shall provide a safe, efficient and secure system for personnel to operate and maintain.

Principles of human factors engineering shall be considered throughout the design of project systems. Instrumentation and controls shall have the capability of monitoring and controlling all parameters necessary for both SPS and long term vault operations. Physical configuration and spacing of fixtures and equipment shall provide for ease of service and operational needs. As much as possible, the design shall utilize standard components that are currently utilized and readily available as spares. 


\section{PROCESS AND STORAGE CRITERIA}

\subsection{SPS Support System Process Criteria}

Process criteria for the SPS shall be governed by the PuSAP contract as discussed in Section 1 . System and process functional criteria for the SPS are described in Appendix B of this document. Process criteria for systems and components which interfaces with the SPS are described in this section.

\subsubsection{Utility Interfaces for SPS}

The following table indicates interfaces specified in the SPS System Specification Document under the PuSAP contract which are the responsibility of this project to design and install. Capacities for each utility shall be verified with the PuSAP contractor during conceptual design:

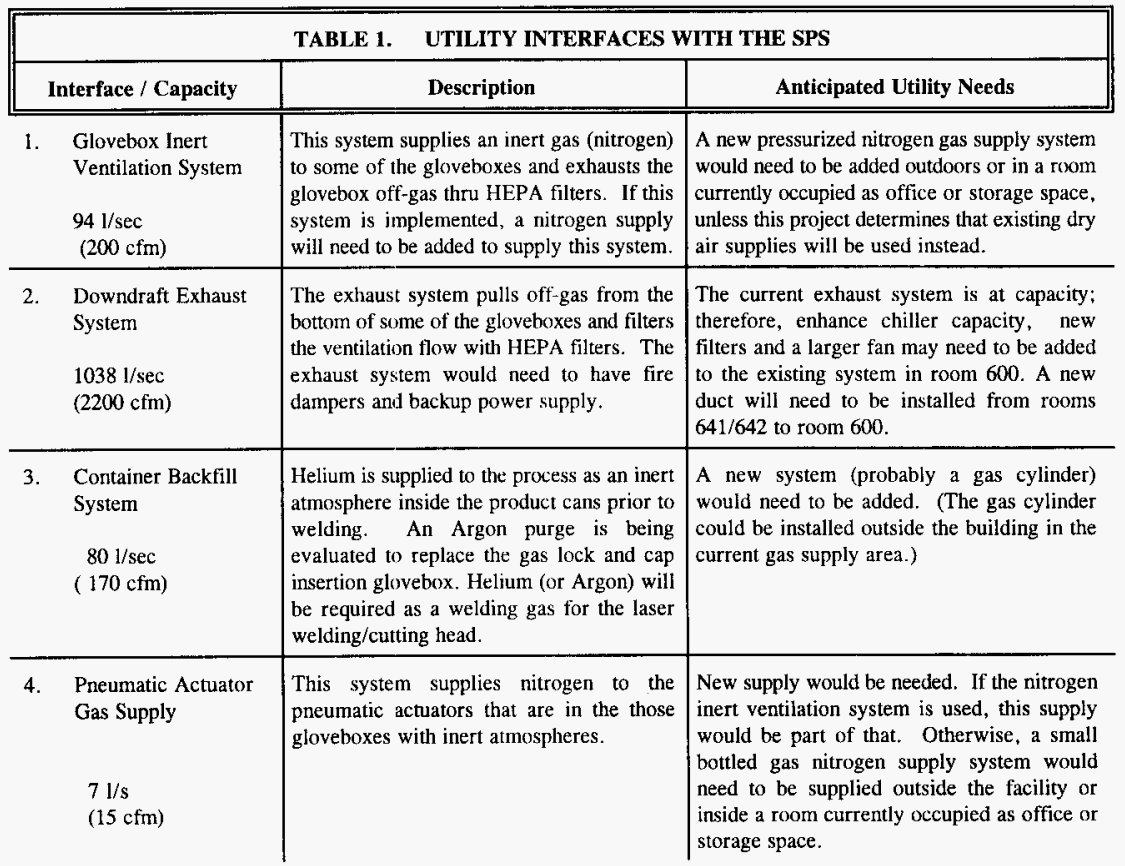




\begin{tabular}{|c|c|c|}
\hline Interface / Capacity & Description & Anticipated Utility Needs \\
\hline $\begin{array}{l}\text { 5. Process Cooling } \\
\text { Water } \\
100 \mathrm{~kW} \\
(341,200 \mathrm{BTU} / \mathrm{hr})\end{array}$ & $\begin{array}{l}\text { This system supplies cooling water to the } \\
\text { generator for the laser welder. }\end{array}$ & $\begin{array}{l}\text { Cooling water provided to the laser will be a } \\
\text { closed loop chilled water unit which will be } \\
\text { installed in the available space in Room } 642 \text {. } \\
\text { Existing lines in the building could provide } \\
\text { up to } 200 \mathrm{gpm} \text { at } 28 \text { psig. }\end{array}$ \\
\hline $\begin{array}{l}\text { 6. Laser Gases } \\
\begin{array}{l}1.5 \mathrm{l} / \mathrm{s} \\
(3 \mathrm{cfm})\end{array}\end{array}$ & $\begin{array}{l}\text { This system supplies the laser with high } \\
\text { purity nitrogen, carbon dioxide, and helium } \\
\text { for the generation of the laser light. }\end{array}$ & $\begin{array}{l}\text { A new system (maybe ultra pure gas } \\
\text { cylinders) would need to be added. (The gas } \\
\text { cylinders would probably be in an enclosure } \\
\text { near the Laser inside the building) }\end{array}$ \\
\hline $\begin{array}{l}\text { 7. Dry Air System } \\
48 \mathrm{l} / \mathrm{s} \\
(102 \mathrm{cfm})\end{array}$ & $\begin{array}{l}\text { This system supplies dry air to the } \\
\text { stabilization furnaces, the LOI furnace, and } \\
\text { the desiccator. }\end{array}$ & $\begin{array}{l}\text { A new line may be needed in addition the } \\
\text { current system in room } 602 \text { (two lines at } 25 \\
\text { cfm). Dry air is available in Corridor } 623 \text {. }\end{array}$ \\
\hline $\begin{array}{l}\text { 8. Plant Air System } \\
24 \mathrm{l} / \mathrm{s} \\
(52 \mathrm{cfm})\end{array}$ & $\begin{array}{l}\text { This system supplies air to the pneumatic } \\
\text { actuators that are in the gloveboxes when } \\
\text { there is no need for inert atmosphere. }\end{array}$ & $\begin{array}{l}\text { A new system would need to be added. If the } \\
\text { nitrogen system is installed, then it maybe } \\
\text { used to supply these actuators and this system } \\
\text { would not be added. }\end{array}$ \\
\hline $\begin{array}{l}\text { 9. 120 VAC Power } \\
\text { Supply System } \\
70 \mathrm{~kW}\end{array}$ & $\begin{array}{l}\text { This system supplies electrical power to the } \\
\text { glovebox lighting and to the low voltage } \\
\text { equipment. }\end{array}$ & $\begin{array}{l}\text { Spare breakers in the current system (room } \\
601 \text { ) could be used to supply the needs of this } \\
\text { system. }\end{array}$ \\
\hline $\begin{array}{l}\text { 10. } 480 \text { VAC Power } \\
\text { Supply System } \\
495 \mathrm{~kW}\end{array}$ & $\begin{array}{l}\text { This system supplies electrical power to the } \\
\text { laser welder unit, muffle furnaces, LOI } \\
\text { furnace, convenience can transfer unit } \\
\text { electromagnet, } 10 \text { 3-HP motors. }\end{array}$ & $\begin{array}{l}\text { The electrical feed to building } 2736-\mathrm{ZB} \text { will } \\
\text { have to be upgraded to handle this new load. } \\
\text { A new electrical panel will need to be } \\
\text { installed for distribution to the SPS. Isolation } \\
\text { dampers will need to be installed on the laser } \\
\text { to prevent harmonic distortion in the rest of } \\
\text { the building electrical system. }\end{array}$ \\
\hline
\end{tabular}

As no indication was made in documentation for the SPS prototype, gas flow amount assumptions are for continuous operation. It is likely that certain large flows will be intermittent, thus overall capacities will be analyzed for reduction at the start of conceptual design. The decision to use nitrogen or dry air for inerting will be made during conceptual design based on anticipated costs.

\subsubsection{Instrumentation and Control}

The project shall modify the existing centrally based utility control (Micon $\left.{ }^{\mathrm{Tn}}\right)$ system for use with the SPS. The location of system controls for the SPS will be determined by this project and coordinated with the PuSAP Contract. All instrumentation and controls necessary to monitor and control operation of support systems for the SPS shall be installed in or near the 2736-ZB Building, and will be co-located with the SPS control system as needed. Where 
feasible, support system controls shall be incorporated within the PC-based SPS controls. Control panels should, where possible, be located at sufficient distance from the gloveboxes and material handling operations to minimize radiological dose to operations staff.

Any software utilized by support systems controllers shall be developed, acquired and used in accordance with -CM-4-2, Quality Assurance Manual, Section QR 19.0 "Software Quality Assurance Requirements". The control configuration shall be documented and verified as described in $\mathrm{QR} 19.0$.

The software acceptance test procedure shall be performed in conjunction with PFP Facilities Engineering personnel and the results documented in an Acceptance Test Report. Functional field tests and an Operational Test Procedure shall exercise all hardware and software components utilized in the performance of the SPS unit with the results demonstrating acceptance performance reported in a Hanford Supporting Document.

\subsubsection{Piping and Vessels}

Piping and vessels for SPS utilities and support systems shall be designed in accordance with applicable ASME codes and standards. All glovebox structures are designated Safety Significant (old Safety Class 3 ) with all piping and vessels inside the glovebox designated as non-safety class (old Safety Class 4) in accordance with HNF-CM-4-46, Safety Analysis Manual. Piping and vessel components shall be made of materials compatible with non safety class operating conditions and shall meet the PFP compressed gas "M-Code", drawing H-2-31750.

The project shall provide for extensive cleaning of piping after construction but before connection to equipment to ensure the lines are free of foreign material. Flushes should include a detergent solution in turbulent flow to remove grease and carry away all particulate material followed by an extensive demineralized water rinse and finally completely dried using a dry nitrogen purge. The lines shall be capped until ready for connection to the equipment. Care shall be used while making the connections to prevent any foreign material from entering the system.

Piping for the utility support system shall have a constant slope with no low spots to ensure complete drainage when flushed.

\subsection{Storage Criteria}

All storage vault fixtures and equipment designed and installed by Project W-460 for long term storage shall be designed to comply with 3013 . It will be necessary to also ensure continued compliance with the Plutonium Finishing Plant Operating Specification for Storage of Special Nuclear Material, OSD-Z-184-00013, for existing SNM packages, until that material is stabilized and repackaged or otherwise dispositioned. 
This project assumes the use of sealed outer storage packages designed by others to comply with the provisions of DOE-STD-3013-96.

Storage of the filled 3013 packages is anticipated for up to 50 years, therefore structural vault modifications should be designed for a 50-year life. Vault fixture modifications to accommodate the containers shall be designed for a minimum 20-year life with replacement anticipated. Major structural components of vault building $2736-\mathrm{Z}$ shall remain intact; modifications shall be made primarily within existing vault storage rooms. Any fixtures or equipment which require penetration of the structural components shall be seismically analyzed to maintain the current seismic Performance Category.

The conceptual design for this project will use cost/benefit techniques to determine the optimum vault storage fixture configuration which meets criteria cited in this document.

Key parameters for design of vault partitions and individual storage fixtures include:

- minimization of cost via consolidation of storage area to increase storage density while maintaining temperature and criticality controls;

- optimizing the design so that human intrusions are minimized, including number of entries and duration, for security, safeguards, maintenance, and repair, and radiological dose reduction purposes; and

- minimization of radiological dose for required entries via design of tools for relatively fast manual retrieval or automation of package retrieval.

\subsubsection{Utility Interfaces}

Electrical power and refrigerated ventilation are required to service the vaults. Both are available or can be made available from within the PFP facility; the conceptual design for this project will determine what modifications will be needed within PFP Complex utilities.

\subsubsection{Electrical}

Room 2736-Z currently has two $240 / 120$ electrical panels (A and E). This project will coordinate with Project C-189 to evaluate the adequacy of current and planned electrical supply to $2736-\mathrm{Z}$ to meet power requirements. It is likely that the power supply for the storage complex will require upgrading to meet capacity requirements.

\subsubsection{Ventilation and Air Conditioning}

The ventilation systems for the storage vaults, the new SPS Process Area and NDA Laboratory, and 2736-ZB occupancy will all require modification to accommodate this project. Ventilation system design for the vaults will provide heat removal, while the system 
for the process area will ensure both heat removal and contamination control. The 2736-ZB room system will provide air conditioning for occupancy. New components of the ventilation systems shall be designed in accordance with DOE Order 6430.1A, General Design Criteria, DOE Order 5400.5, Radiation Protection of the Public and the Environment, and ASME N510-1989, Testing of Nuclear Air Treatment Systems. Existing ventilation systems will not require upgrades to meet current design codes, however any major new ventilation system components shall meet the current design requirements for new systems.

The total volume of air handled for the storage vaults shall be the minimum required for continuous cooling and via relative pressure zones, and shall include the infiltration air from outdoors. Likewise, the air handled for the process area in 2736-ZB shall be the minimum required for continuous cooling and contamination control via relative pressure zones, and shall include the infiltration air from outdoors. The room occupancy system shall provide enough air flow to maintain a comfortable work environment per DOE Order 5480.11, Radiation Protection for Occupational Workers.

Sufficient redundancy and/or spare capacity shall be provided as necessary to ensure adequate ventilation during normal operations and DBA conditions. Refer to Appendix A and WHC-SD-CP-SAR-021, PFP Final Safety Analysis Report (FSAR), Section 5.2.3.7, for a functional and physical description of the system. It is permissible that the ventilation systems fail static during a DBA, provided that each system remains physically whole to provide radiological confinement.

Should personnel entry or intermittent occupancy be the limiting factor in vault ventilation system design, operational provisions such as cool suits will be made for portable equipment when entry to the vaults is required.

\subsubsection{Ventilation Zones}

Facility ventilation for the $2736-\mathrm{Z}$ complex shall be zoned as specified in PFP FSAR, Sections 5.4.1 and 5.4.1.1.7, with a separate zone for the new SPS Process Area. The differential pressures described shall be with respect to atmosphere and shall be considered minimum. Airlocks and other barriers shall be provided as required to separate zones to ensure ventilation balance and contamination control and to maintain pressure differentials. A minimum $31 \mathrm{~Pa}(0.125$-in $\mathrm{wg})$ differential pressure shall be maintained between adjacent zones.

Inlet filtration shall be designed to enhance the flow of makeup air from outdoors while ensuring a minimum capture of dust under high-wind conditions.

Storage conditions shall be in accordance with those described in 3013, which may require enhanced mechanical chilling of makeup air. 
Back flow of contamination from the potentially contaminated ventilation supply flows to the SPS Process Area rooms and gloveboxes shall be prevented via dampers or high-efficiency particulate air (HEPA) filtration.

\subsubsection{Vault Storage Capacity}

A minimum of $4000 \mathrm{~kg}(8800 \mathrm{lb})$ Plutonium in the form of oxides at $50 \mathrm{wt} \% \mathrm{Pu}$, totaling about $8000 \mathrm{~kg}(17,600 \mathrm{lb})$ bulk weight, needs to be stored in packages as described in 3013 . The storage configuration is anticipated to be constrained by heat removal capacity and criticality controls.

Vault storage capacity and density must meet codes and standards for Safety Class (old safety class 1 ), with particular attention to temperature control, seismic and criticality requirements. Criticality and required maximum long term temperature conditions will determine the exact vault storage density.

Agreement with the IAEA is likely to continue the current specification that vault inventory under IAEA surveillance be kept physically separate from the rest of the PFP inventory, making it necessary to consider an entire vault room for the IAEA material. The total number of rooms to be modified will be determined by allowable storage density. 


\section{FACILITY CRITERIA}

\subsection{Architectural and Civil/Structural}

Design of components and systems to be installed in the 2736- $\mathrm{Z}$ Complex must not interfere with the seismic resistance of existing structures. This project shall provide control connections to enable future complete ventilation system control (both automatic and manual) from the $2736-Z$ complex area, to facilitate eventual shutdown of the $234-5 \mathrm{Z}$ ventilation control room while the storage vaults remain operating.

All construction, occupancy ratings, and existing building requirements will be governed by the more restrictive of the NFPA or UBC Codes.

This project shall provide calculations of the rate of heat rise during static vault conditions such as the aftermath of a DBA, in order to assure that the structural design of vault storage fixtures provides convective cooling in case of a ventilation system failure prolonged for several weeks.

\subsection{Heating, Ventilation, Air Conditioning}

Background information on the existing heating, ventilation, and air conditioning systems in the 2736-Z Complex can be found in Appendix A.

Ventilation for all equipment installed for this project shall exhaust to the 296-Z-5 stack through a minimum of two testable HEPA filtration stages.

SPS interface design shall include glovebox and fume hood gas supplies (air, nitrogen, dry air); exhaust is to be provided by connection and modification to the existing 2736-ZB ventilation system unless a new system is required for overwhelming mechanical reasons. Heat loading and zone control shall be evaluated in this project's conceptual design. Room ventilation requirements shall be analyzed for adequacy. An evaluation will be required to ensure the existing exhaust system capacities and configurations are adequate for the SPS and for the increased density of containers in the modified vault storage rooms.

All nuclear grade filtration equipment and components will be constructed to American Society of Mechanical Engineers (ASME) N509 and tested to requirements of ASME N510.

The addition of larger calorimeters and the staging of 3013 packages in the NDA Laboratory may require a change in the capacity of refrigerated ventilation to that area to effectively maintain constant working temperatures. 


\subsection{Utilities}

Utility support services shall comply with DOE/RLID 5480.7A, Glovebox Fire Protection Criteria. The following new or enhanced utility supplies are required for SPS operation:

- Helium System (for container backfill),

- Nitrogen System (for pneumatics and inert ventilation system),

- Dry Air System (for furnace area),

- Room ventilation (existing HEPA filters),

- Downdraft Exhaust System from Gloveboxes,

- Process Cooling Water for Laser (process water available),

- Laser Gases (high purity nitrogen, carbon dioxide, and helium),

- Plant Instrument and Process Air System (for some instruments and pneumatics),

- 120 VAC $60 \mathrm{HZ}$ Power Supply System (Lighting, Equipment and Controls),

- 480 VAC 3-Phase 60 HZ Power Supply System,

\subsubsection{Process Water}

Closed loop cooling is preferred for the Laser generator, using a nonhazardous recirculating fluid. Water for fire suppression (ie., room sprinklers) is available via existing supply lines to the building fire suppression sprinkler pipe system. Corridor 625 has a $.1 \mathrm{~m} \mathrm{(2} \mathrm{in.)} \mathrm{pipe}$ with up to $757 \mathrm{lpm}(200 \mathrm{gpm})$ capacity.

There are no direct connections to the 243-Z Low Level Waste Treatment Facility (LLWTF) from $2736-\mathrm{Z} / \mathrm{ZB}$. If there is an overwhelming necessity, a pipeline for used process water could be installed to connect to $243-Z$.

\subsubsection{Electrical}

Electrical supply capacity shall be evaluated by the conceptual design and coordinated with project C-189, Plutonium Finishing Plant Standby Diesel Generator Upgrades. The 480 volt three-phase power supply to 2736-ZB will be upgraded to accommodate the loads added by this project and to provide $25 \%$ spare capacity for future load additions to 2736-ZB. The Plutonium Stabilization and Packaging System requires 120 volt single phase and 480 volt three phase power. The capacity requirements for each feed will be estimated during conceptual design.

The upgraded power supply shall have a single 480 volt, three phase, normal power feed from site electrical distribution and a single 480 volt, three phase, back-up power feed from 2721-Z. At the point of connection to 2736-ZB power distribution system, power feeders for the Plutonium Stabilization and Packaging System shall meet the requirements of IEEE-591, "IEEE Recommended Practices and Requirements for Harmonic Control in Electrical Power Systems." 


\subsubsection{Lighting}

Basic room lighting for the SPS installation and operation will be provided by the existing building lighting system. Any additional task lighting will be determined and added by definitive design. Temporary lighting for construction will be provided on an as needed basis. Modifications of task lighting may be required in the storage vaults, depending on storage fixture configuration and security requirements.

\subsection{Communications Systems}

Communications will be installed in the SPS operating area, as required. These will include an intercom (Private Automatic Exchange / PAX) phone for internal use, and a public telephone, and a tie-in to the PFP talk-box system. All communications systems now located in the 2736-Z complex shall be analyzed for adequacy and modified as necessary due to rearrangements in various facility work spaces.

\subsection{Automatic Data Processing}

Any new automatic data processing desired will be incorporated into the SPS operating control system or the NDA Laboratory control computers, as required. Data removal will be by media such as diskette or removable hard drive for subsequent analysis.

\subsection{Energy Conservation}

All facility modifications, including the SPS, shall be designed to maximize energy conservation where feasible.

\subsection{Maintenance}

All facility modifications and equipment shall be designed to permit routine maintenance activities and reduce the need for specialized equipment wherever practical and cost effective. Operating systems shall minimize exposure to hazardous or radioactive environments. ALARA practices shall be incorporated into all design for the maintainable and replaceable components as well as all maintenance activities. Equipment selections should be standard components whenever possible.

Mechanical and electrical systems shall be easily maintainable as defined by the demonstrated replacement of wear-critical parts within two hours. Space shall be provided adjacent to all equipment and confinement systems to allow easy access for maintenance.

Design for this project will include ease of maintenance such that any maintenance task should generate no more waste than an equivalent operating shift operation. 


\section{GENERAL REQUIREMENTS}

\subsection{Safety}

\subsubsection{Safety Classifications}

The filtration, seismic, criticality, and offgas monitoring components and systems of the vault storage rooms, the NDA Laboratory and the SPS must be designed to meet Safety Class (old safety class 1) requirements. The SPS gloveboxes must be designed to meet Safety Significant (old safety class 3 ) requirements. A draft of modifications to the PFP Safety Equipment List will be produced during the advanced conceptual design, to include the systems, structures and components installed and modified by this project. Other facility modifications shall not be safety significant unless a postulated accident scenario is shown by the Preliminary Safety Evaluation (PSE) to require that classification.

\subsubsection{Criticality}

All components and systems shall be designed, fabricated and operated to remain sub-critical for all fissile materials to be stabilized or stored in PFP. Since there is a potential for critical concentrations of fissile material in the SPS and in storage areas, criticality analyses shall be provided. All storage units, equipment, vessels, and piping shall be geometrically favorable to prevent criticality. Project designs shall conform to requirements listed in HNF-CM-4-29, Nuclear Criticality Safety Manual, Section 2.0.

The Criticality Safety Evaluation Reports (CSER) for the storage vaults and NDA laboratory shall be updated to reflect new equipment configurations. A separate CSER shall be provided for the SPS and related equipment, based on preliminary work provided by the vendor.

\subsubsection{Safety Analysis}

The current revisions of the PFP FSAR provides the release analysis and limits for plutonium possession in the facility. Preliminary analysis shall be performed during the conceptual design to verify whether the addition of the SPS would change the possession limits and whether criticality limits to be applied to the project would affect the PFP Authorization Basis.

A Preliminary Safety Evaluation (PSE) shall be completed in conjunction with the conceptual design. Detail descriptions, accident analyses and descriptive changes to the FSAR shall be completed prior to acceptance of the completed project. 


\subsubsection{Contamination Control}

All structures, systems and equipment designed for this project shall confine contamination to the vicinity of the source and minimize contamination spread. Confinement shall be achieved by ventilation control (differential pressure), by directing air from uncontaminated areas toward areas of higher contamination, by high-efficiency particulate air (HEPA) or equivalent filtration or equivalent back flow isolation, and by the use of controlled personnel traffic patterns. The cross-contamination of work areas by airflow shall be minimized. An additional source of vacuum to support continued operation of the continuous air monitors (CAM) shall be provided when the existing vacuum system for the room and stack CAMS is inoperable.

\subsubsection{Radiation Exposure}

The maximum annual exposure to a facility worker from all sources must not exceed the cumulative limits set forth in 10 CFR 835, Occupational Radiation Protection, and in HSRCM-1, Hanford Site Radiological Control Manual, summed over all controlled access areas. The radiation exposure of each operations worker is limited to no more than 2.0 rem per year, with administrative controls (HSRCM-1, Article 212) and a worker monitoring program which provide hold points starting at a cumulative exposure to any worker at 0.5 rem. Where necessary, shielding shall be provided to maintain personnel radiation exposure levels ALARA as governed by 10 CFR 835, Subpart K, and DOE Order 5480.11, Radiation Protection for Occupational Workers. Guidelines for achieving exposure levels that are ALARA are contained in PNL 6577, "Health Physics Manual of Good Practices for Reducing Exposure to Levels that are as Low as Reasonably Achievable (ALARA)" and DOE/EV/1830.T5, "A Guide to Reducing Radiation Exposure to As Low As Reasonable Achievable (ALARA)." The source term used for shielding design should be the maximum expected during normal operation. Source terms which may develop in operating and storage areas shall be considered. Requirements to minimize background radiation levels shall also be considered.

Maximum annual dose limits to the public as a result of PFP operations shall be in accordance with WHC-SD-CP-SAR-021, PFP Final Safety Analysis Report. Where there is potential for airborne contamination, allowance shall be made for internal deposition of radionuclides in determining the total dose. Maximum allowable airborne contamination levels are provided in HSRCM-1.

There are varying levels of americium ingrowth in the plutonium stored at the PFP. For the calculation of radiation exposures, levels from zero to $15 \mathrm{~g}^{241} \mathrm{Am}$ per $5 \mathrm{~kg}$ of Pu oxide should be considered. Assume self-shielding from the material itself. 


\subsubsection{Radiation Exposure During Maintenance and Decontamination}

Consideration shall be given to maintenance and decontamination activities associated with a given design option. Design shall be planned to confine total per capita worker radiation exposure to less than 500 mrem annually. In no case shall personnel participating in maintenance and decontamination exceed an effective dose equivalent of 1,000 mrem/year. Exposure rate limits apply at points where personnel are located during a particular maintenance or decontamination activity as opposed to general areas. Access categories may be temporarily changed when required for maintenance and decontamination.

\subsubsection{Industrial Safety}

Hazards involved in this project will be eliminated or reduced through implementation of safety and health standards, procedures and policies in HNF-CM-1-10, Safety Manual. In addition to common construction hazards, work involving electrical circuits will be in accordance with section 15 "Electrical Work Safety" and section 16 "Electrical Installation Safety" of the Safety Manual.

\subsubsection{Industrial Hygiene}

Design and construction shall assure compliance with applicable industrial health and safety standards (29 CFR 1910 and 1926), HNF-CM-4-40 and HNF-CM-1-11, and the most recent consensus standards applicable to occupational safety and health (e.g. ACGIH Threshold Limit Values for Chemical Substances and Physical Agents and Biological Exposure Indices).

\subsubsection{Fire Protection}

Facility modifications (including vault equipment, gloveboxes and glovebox fire detection and suppression systems) shall be designed in accordance with DOE/RLID 5480.7, "Fire Protection"; RLID 5480.7A "Glovebox Fire Protection Criteria"; and applicable NFPA standards, including NFPA 801, the standard for Facilities Handling Radioactive Materials.

Overheat detection shall be provided in all gloveboxes, spaced at a minimum of 8 foot levels. Areas of ambient heat will require the proper temperature heat detector. Automatic fire suppression shall be required if the atmosphere within a glovebox contains more than 5 percent oxygen.

The fire fighting category for areas of the $2736-\mathrm{Z}$ complex modified by this project shall be analyzed and updated during advanced conceptual or definitive design.

\subsubsection{Container Surveillance During Storage}

The laboratory equipment required for safeguards needs (see Section 5.3.1.1) also supports a safety function for surveillance of packages in storage. In addition, since existing means 
of verification that pressurization is not taking place are not suitable for use with the 3013 packages, space for a radiography unit capable of verifying the physical condition of package contents will be set aside as a good practice item. Site preparation for these items will be undertaken in sequence to minimize disruptions to NDA. laboratory operations.

Results of an inventory characterization program now ongoing at the PFP and not slated to end prior to installation of the SPS may indicate the need for other laboratory equipment beyond calorimetry, gamma scan and radiography units for operational safety surveillance once the inventory is contained in 3013 packages. Any additional equipment needed shall be specified during advanced conceptual design or detail design of this project.

\subsection{Environmental Protection and Compliance}

A Notice of Construction (NOC) shall be prepared and submitted to the State of Washington Department of Health and the U.S. Environmental Protection Agency prior to construction. All work that will be performed that has the possibility of radiological or non-radiological emissions shall be brought to the attention of the PFP air emissions engineer.

The installation of the SPS will result in changing the designation of the 296-Z-5 stack under the 40 CFR 61, National Emission Standards for Hazardous Air Pollutants (NESHAP), from a 'minor' stack to a 'major' stack. This change in status may require upgrade of the stack monitoring equipment to meet the requirements of 40 CFR 61, Subpart H. Any stack monitoring upgrades required solely because of this redesignation will be within the scope of this project and will be consistent with Project W-420 "Stack Monitoring System Upgrades".

All solid waste that will be generated during installation and operation of the SPS shall be reviewed by the PFP solid waste engineer, and disposed of properly.

No services are currently provided for treating industrial wastewater discharges from 2736-ZB. Cooling water for the SPS may constitute a potentially contaminated effluent route. If so, the project must make provisions for routing the wastewater to the $243-\mathrm{Z}$ facility for treatment prior to discharge to the Treated Effluent Disposal Facility.

The Plutonium Finishing Plant Stabilization Environmental Impact Statement provides basic National Environment Policy Act (NEPA) documentation for this project. However, a review will be conducted to verify any supplemental documentation needed for operation of the systems installed by this project.

A cultural resource review has been completed for PFP stabilization activities. The Memorandum of Agreement to mitigate the historical significance documentation for the Plutonium Finishing Plant complex has been approved by the Department of Interior. No further review is required. 


\subsection{Safeguards and Security}

While the overall amount of SNM in the storage vaults will not change appreciably due to this project, the type, quantity and distribution of SNM in 2736-ZB is likely to change from current levels. Both the SPS and the NDA Laboratory will contain Safeguards Category I types and amounts of SNM during stabilization and packaging operations, which will require changes to physical protection and certain security boundaries.

The processing of SNM requires physical protection as outlined in the Department of Energy orders: DOE 5632.1C "Protection and Control of Safeguards and Security Interests" and DOE 6430.1A "General Design Criteria". Material tracking and accountability requirements are provided in the Department of Energy order DOE 5633.3B "Control and Accountability of Nuclear Material".

For purposes of safeguards related design and operations, an SPS Processing Area will be defined as the contiguous area consisting of rooms 638,641 and 642 . The boundaries will be defined by the North, East and West walls of room 638; the East and West walls of room 641; and the South, East and West walls of room 642 .

The storage vaults, NDA Laboratory and the SPS Processing Area will be contained within the existing 2736-Z Material Access Area (MAA). Access to the MAA and storage vaults will be controlled by the protective force and Central Alarm Station. The MAA and vault doors are equipped with balanced magnetic switch sensors. The interior and exterior of the MAA vault doors are monitored by closed circuit television (CCTV) cameras.

Authorized access into the SPS Processing Area (including the control room), the NDA Laboratory and the storage vaults will be controlled by enforcing a "two person rule" system. The two person rule will ensure that at least two knowledgeable people in the Personnel Security Assurance Program are in the area when work is progress. These areas are equipped with an access denial system that may have to be updated depending on final configuration and DOE guidance anticipated prior to project completion.

From a safeguards perspective, consideration should be given to the separation of material storage room 638 from operation rooms 641 and 642 via a wall which meets vault boundary requirements, including the area above the dropped ceiling in each room. The existing wall between 638 and 641 is stud and drywall construction which does not meet requirements for a vault room.

A security vulnerability risk analysis for this area will be included as part of a routine annual update, and is not included within this project. 


\subsubsection{Safeguards Material Control and Accountability}

\subsubsection{SPS Unit}

Capability shall be provided for all necessary nuclear material accounting data generated by the SPS to be transmitted to the PFP nuclear material accounting system. This may be accomplished via remote or manual instrumentation, and/or provision for manual collecting of data.

Capability for clean out or measurement of holdup and scrap nuclear materials shall be a design feature of any equipment provided by Project W-460 which will directly contact SNM, in particular the SPS. The design must accommodate daily administrative checks and a physical inventory every 2 months, with a limit-of-error for inventory differences of less than the smaller of a Category II quantity of special nuclear material or $2 \%$ of total throughput and active inventory.

Provision shall be made for access to appropriate nuclear material measurement systems to assure compliance with domestic safeguards limit-of-error for SNM inventory difference requirements. A safeguards knowledgeable statistical analysis shall define and allocate acceptable uncertainty values to each component of the measurement system.

Package components and the completed packages shall meet safeguards requirements for Category I types and amounts of SNM. Pertinent safeguards concepts embodied in the design of the 3013 package include a permanent and unique item identification number, an inherent tamper-indicating design, and a physical structure which permits accurate NDA assay of the contents.

Support capabilities shall be provided to permit appropriate sampling for destructive analysis prior to packaging, as well as the opening and repackaging of 3013 packages. Both domestic and international safeguards may require sampling on a periodic basis during processing; it is not yet clear whether sampling for destructive analysis will be required during periodic SNM inventories after processing. The requirement for sampling includes provision of a means to assure that particles in the batch to be sampled are relatively uniform in nature (if the material is not a powder, a crushing device will be needed) and well-mixed (requires a blender) and a balance which is accurate per safeguards standards plus a means of transferring the sample away from the sampling area to the laboratory.

\subsubsection{Plutonium Storage Vault}

Existing safeguards vault instrumentation is incompatible with the 3013 package; all items shall be analyzed and functions continued via modifications as required by DOE Order 5633.3. Near real time container identification, tamper indication, and nuclear material verification are required to support domestic safeguards inventory requirements. Active portions of safeguards equipment for the vault rooms shall be located outside the vault rooms 
to allow for replacement or repair without vault access, a feasible. Components shall be reused if appropriate for use with 3013 packages and economically feasible.

The vault fixture design shall permit the removal of containers from storage locations for repackaging, sampling, or measurement for domestic or international safeguards purposes. Container handling may be manual or remote, depending on modeling which predicts package temperature and dose rates.

\subsubsection{Interface with International Atomic Energy Agency}

Storage of a portion of the PFP SNM inventory is maintained under an agreement between the United States and the IAEA per IAEA Information Circular/288. Modifications to packaging and storage conditions for these materials will require further agreement between the United States and the IAEA and continued compliance with Safeguards Criteria, TS-No.\#3, 1994-04-15 . The outcome of negotiations being prepared in a parallel effort to this project will affect equipment design in the storage vaults.

Where possible project design shall take into account measures which would allow joint IAEA and operator use of vault inventory measurement and surveillance equipment. Specific design requirements relating to this concept shall be developed during discussions between the IAEA, contractor safeguards, and the design agency prior to finalization of the conceptual design.

Containment and Surveillance $(\mathrm{C} / \mathrm{S})$ requirements of the IAEA shall be met in the storage vault design per IAEA Technical Standard TS-No.3. "Containment and Surveillance" is a specialized security term which embodies physical measures to keep nuclear material secure (containment) and to detect the presence of specific nuclear materials in a specific location (surveillance). The IAEA requires Dual $\mathrm{C} / \mathrm{S}$ for storage vaults under their purview, ie., for each location, two independent methods of containment and two independent methods of surveillance are employed as a check and balance. As feasible, Triple $\mathrm{C} / \mathrm{S}$ features shall be included in the vault design to assure that Dual $\mathrm{C} / \mathrm{S}$ can be maintained at all times, even during failure of one method of either containment or surveillance. The assurance of Dual $\mathrm{C} / \mathrm{S}$ can reduce the cost of future IAEA safeguards activities by taking advantage of rules which permit less frequent and less intensive inspections if these measures have been maintained between inspections by the IAEA.

\subsection{Natural Forces}

The PFP Vault Storage Facility, Building 2736-Z, was designed to Hazard Class II, Performance Category 3 for seismic resistance. The PuSAP contract has designated the SPS to be seismically qualified, as the building the prototype unit will be operated cannot be strengthened to qualify. Therefore, the SPS unit to be installed at the PFP will also be designed to the same 
class, providing an extra margin of seismic safety. The PFP FSAR contains restrictions on the quantities of plutonium that may be released in a seismic event. The PSE will verify if any other natural phenomena events need be compensated for in the designs for this project. All plutonium handled outside of the SPS shall be contained as required for storage vault items. Design of SPS interface items, laboratory and storage components shall assure that no component jeopardizes the facility classification.

All other equipment shall be secured as required by the UBC revision in effect at the time of construction. The project is anticipated to be within the analyzed bounds of the PFP Authorization Basis for natural phenomena.

\subsection{Design Format}

Drawings that interface with existing PFP facility drawings shall provide traceability to these existing drawings by identifying the affected Hanford drawings in accordance with WHC-CM-6-3, Drafting Standards Manual.

Modifications which affect the accuracy or completeness of any Essential Drawing identified in WHC-SD-CP-TI-125, PFP Essential and Support Drawing List, shall require that revision of the affected Essential Drawing be completed by the Project.

Equipment Component Identifier numbers designated for new equipment shall be defined in accordance with WHC-SD-CP-RD-024, Component Identifying Standard for the PFP.

\subsection{Quality Assurance}

Quality Assurance and Quality Control services shall be provided for design specification, design media, materials procurement, fabrication, installation and acceptance testing activities. Requirements imposed by and derived from 10 CFR 830.120 shall be implemented using a graded approach to assure that customer requirements are met and that the final installation will perform as the designers intended.

Reviews, Inspections, and other Oversight services shall be supplemented with any additional services defined by the designers and fabricators as being essential to assuring the success of their efforts. All work performed On-Site and Off-Site shall be performed in accordance with an approved QAP/IP, which shall implement 10CFR830.120. The QAP/IP of an Off-Site vendor shall be approved by the designated Hanford contractor prior to the start of definitive design.

\subsection{Decontamination and Decommissioning}

All structures, systems and components shall be designed to limit dispersion of radioactive materials, and facilitate decontamination and decommissioning or reuse. All readily accessible surfaces should be finished (ground, polished, painted, etc.) to facilitate decontamination. Components anticipated to contact radionuclides should be designed for easy disassembly using 
common tools, to the extent practical. Disassembled components should be compact enough to fit in an existing type of disposal package such as a 208 liter ( 55 gallon) drum.

The establishment of radiological buffer areas within the SPS operating room that would allow for access to finishing end workstations without Personal Protective Equipment should be considered in determining placement. Auxiliary equipment which has no requirement to be placed in a surface contamination area should be located in a buffer zone if practical.

\subsection{Operating Personnel and Services}

The personnel necessary for operation of the SPS unit, NDA Laboratory and storage vaults will be increased beyond the current totals at the 2736-Z Storage Complex until completion of packaging for the existing SNM inventory. Additional personnel will be provided from within the PFP staff.

It is important that the conceptual design of this project consider minimizing of radiation dose to be a particularly important parameter, as the dose levels due to manual handling of inventory in existing containers are expected to be very high. Minimum staff totals for safe operation are anticipated as follows:

- Five nuclear process operators, a crew supervisor, two health physics technicians, a custodian, a chemist and two NDA technicians comprise the minimum crew for each shift that the SPS unit and NDA laboratory operate. Staging of incoming SNM from the storage vaults to the SPS and back again would be anticipated one shift each day (five shifts each week) The operations crew would be split to handle this task along with operation of the SPS unit itself.

- Prior to vault fixture modification, a major task of inventory shifting will be required to empty each room in turn. This task will likely take place over the next three years in periodic activities. The schedule for inventory shifting shall be coordinated with physical inventory movements and other necessary movements to minimize the radiation dose to qualified staff. This task is anticipated to require three nuclear process operators, two health physics technicians and two custodians for concentrated subtasks of one to two weeks each on day shift. Estimates of total dose from these movements shall be conducted during the advanced conceptual design phase of this project.

- During SPS campaigns, maintenance craftsmen would be anticipated to include an instrument technician, pipefitter, mechanic and an electrician to be on call for each shift that the SPS unit operates. A weekend maintenance schedule would be followed, with a double crew (eight craftsmen and a supervisor) working two shifts each weekend to maintain the SPS fully operational 
After the inventory has been packaged and placed in the modified vault storage fixtures, staff needs will be reduced to current (1996) levels or less. Reductions in staff can be achieved in anticipated changes to safeguards requirements allow reduced inventory frequencies.

\subsection{Human Factors Considerations}

Human factors engineering shall be considered for all phases of design in this project.

Operation of the SPS unit shall be primarily monitored and controlled from a remote control interface (computer) in a single location, as feasible. This location will be within view (either direct or via camera) of the SPS but in a location to limit personnel exposure to ALARA.

All interface/workstations shall allow for varying staff ergonomics and shall be sealed as feasible to allow for easy decontamination.

All hand-operable equipment shall be positioned such that it can be seen by the operator during manipulation. Any support equipment requiring operation while in the SPS operating room must be easily accessible (if within a glovebox, from glove ports) to allow for maintenance. As much as possible, hand-operable equipment shall be consolidated in a minimal number of gloveboxes to expedite operations.

Both intercom (PAX) and normal phone lines shall be within several feet of any control interface/workstation.

The necessity and feasibility of connection to the Hanford Computer Local Area Network (LAN) for the remote control interface shall be evaluated and determined by PFP Process Engineering.

\subsection{Testing}

Acceptance testing of the SPS is part of the PuSAP contract; this testing will be integrated with project testing as applicable. Operational testing will be conducted on the SPS and support systems by PFP staff after the SPS has been received by the PFP. Acceptance testing and operational testing of vault modifications and laboratory equipment shall be scheduled in phases and conducted as appropriate. Operational testing of the SPS may be conducted using stand-in material for plutonium oxide as cerium oxide, to be determined by PFP Process Engineering. 


\section{APPLICABLE CODES AND STANDARDS}

If no version number is shown below, the most current revision of the documents listed shall be considered part of the functional criteria for this project. In the event of conflict between a general requirement document listed below and specific criteria in this document, the specific criteria shall be considered to supersede the general requirement.

Applicable Federal, State, and local laws and regulations, and DOE orders and standards, in effect at the start of the design shall apply to the extent specified in the Plutonium Finishing Plant Standards/Requirements Identification Document, WHC-SD-MP-SRID-003 (S/RID). International agreements applicable to the PFP in place as time of publication of this document are also listed. It is recognized that additional agreements may be negotiated during the detail design and implementation of this project.

\subsection{International Agreements}

IAEA, TS-NO.\#3, 1994-04-15, "Safeguards Criteria"

IAEA Information Circular/288, December 1981, "The Text of the Agreement of 18 November 1977 Between the United States Of America and The Agency For The Application Of Safeguards in the United States Of America".

\subsection{Federal Rules and Guidelines}

10 CFR 830.120, "Nuclear Safety Management Quality Assurance"

10 CFR 835, "Occupational Radiation Protection"

29 CFR 1910, "Occupational Safety and Health Standards"

29 CFR 1926, "Safety and Health Regulations for Construction"

40 CFR 61, "National Emission Standards for Hazardous Air Pollutants"

40 CFR 262, "Standards Applicable to Generators of Hazardous Waste"

41 CFR 101-19.6, "Accommodations for the Physically Handicapped"

49 CFR 178, "Specification for Packaging"

42 USC $\S \S 2011$, "Atomic Energy Act"

42 USC $\$ \S 4321$, "National Environmental Policy Act of 1969"

42 USC $§$ 6901, "Resource Conservation and Recovery Act"

G-830.120, Implementation Guide for Use with 10 CFR Part 830.120, Quality Assurance Requirements 


\subsection{Department of Energy National Orders, Contracts and Guidelines}

DOE 5400.5, "Radiation Protection of the Public and the Environment"

DOE 5480.7A, "Fire Protection"

DOE 5480.10, "Contractor Industrial Hygiene Program"

DOE 5480.11, "Radiation Protection for Occupational Workers"

DOE 5480.24, "Nuclear Criticality Safety"

DOE 5632.1C, "Protection and Control Of Safeguards and Security Interests"

DOE 5633.3B, "Control and Accountability of Nuclear Material"

DOE 6430.1A, "General Design Criteria"

DE-AC03-96SF20948, "Stabilization and Packaging Systems"

DOE/EH-0256-T, DOE Radiological Control Manual

DOE/EM/0199, "Plutonium Vulnerability Management Plan"

DOE/EV/1830.T5, "A Guide to Reducing Radiation Exposure to As Low As Reasonable Achievable (ALARA)"

DOE-STD-1020-94, Natural Phenomena Hazards Design and Evaluation Criteria for Department of Energy Facilities

DOE-STD-1021-94, Natural Phenomena Hazards Performance Categorization Criteria for Structures, Systems and Components

DOE-STD-3013-96, "Criteria for Safe Storage of Plutonium Metals and Oxides"

\subsection{National Consensus Standards}

ACGIH, Threshold Limit Values for Chemical Substances and Physical Agents and Biological Exposure Indices

ACI-349, Code Requirements for Nuclear Safety Related Concrete Structures

AG-1, Code on Nuclear Air and Gas Treatment Systems, 1991; with Addendum SA of 1993

American Glovebox Society, Guidelines for Gloveboxes

ANSI/AISC N690, Nuclear Facilities -- Steel Safety-Related Concrete Structures for Design, Fabrication and Erection

ANSI B19, Safety Code for Compressed Air Machinery, 1938

ANSI N14.5, Standard for Radioactive Material, Leakage Tests on Packages for Shipment ANSI Z136.1, Standard for Safe Use of Lasers, 1993 
ANSI/ANS-8.1, Guide for Nuclear Criticality Safety in the Storage of Fissile Materials, 1975.

ASCE 4, Seismic Analysis of Safety Related Nuclear Structures and Commentary

ASCE 7, Minimum Design Loads for Buildings and Other Structures

ASME N509-1989, Nuclear Power Plant Air-Cleaning Units and Components

ASME N510-1989, Testing of Nuclear Air Treatment Systems

IEEE-591, IEEE Recommended Practices and Requirements for Harmonic Control in Electrical Power Systems

NFPA 70, National Electrical Code

NFPA 72, National Fire Alarm Code

NFPA 101, Life Safety Code

NFPA 801, Standard for Facilities Handling Radioactive Materials

Uniform Building Code

Uniform Fire Code

\subsection{Washington State Regulations}

Washington Administrative Code (WAC) 173-303, "Dangerous Waste Regulations" WAC 246-247, "Radiation Protection for Air Emissions"

\subsection{Hanford Implementing Directives and Manuals}

This project will comply with all Department of Energy, Richland Office, Implementing Directives and Hanford manuals according to the PFP S/RID. All site-wide manuals were re-designated to start with "HNF" in December 1996, and are referred to within this document in that manner for ease of retrieval. The documents shown below are highlighted for special attention during the project:

RLID 5480.7, "Fire Protection"

RLID 5480.7A, "Glovebox Fire Protection Criteria"

RLIP 4700.1A, Attachment V, "Functional Design Criteria"

HSRCM-1, "Hanford Site Radiological Control Manual"

HPS-SDC-4.1, "Design Loads for Facilities" 


\subsection{Technical Documents}

LA-10860-MS, Critical Dimensions of Systems Containing ${ }^{235} \mathrm{U},{ }^{239} \mathrm{Pu}$, and ${ }^{233} \mathrm{U}, 1986$ SAIC/RFFO-96-003, Loss on Ignition (LOI) Measurements on Plutonium Oxide, 1996

UCRL-15673 (University of California), Human Factors Design Guidelines for Maintainability of Department of Energy Nuclear Facilities, 1985 


\section{REFERENCES}

BNFL, 1996a, "System Specification for the Plutonium Stabilization and Packaging System -Contract No. DE-AC03-96SF20948 -- CDRL Sequence No. A001", British Nuclear Fuels Limited, Inc., Denver, Colorado.

BNFL, 1996b, "System Design Document for the Plutonium Stabilization and Packaging System -- Contract No. DE-AC03-96SF20948 -- CDRL Sequence No. A002”, British Nuclear Fuels Limited, Inc., Denver, Colorado.

DNFSB, 1994, "Recommendation 94-1 to the Secretary of Energy, pursuant to 42 U.S. C. $\$ 2286$ a(5) Atomic Energy Act of 1954, as amended," Defense Nuclear Facilities Safety Board, Washington, D.C.

DOE, 1996a, Hanford Site Radiological Control Manual, Rev. 2, HSRCM-1, U. S. Department of Energy, Richland, Washington.

DOE, 1996b, "Stabilization and Packaging System," Contract DE-AC03-96SF20948 as amended, U. S. Department of Energy - Oakland Operations Office, Oakland, California.

DOE, 1996c, DOE-STD-3013-96, "Criteria for Safe Storage of Plutonium Metals and Oxides", U. S. Department of Energy, Washington, D.C.

PNL, Health Physics Manual of Good Practices for Reducing Exposure to Levels that are as Low as Reasonably Achievable, , PNL-6577, Pacific Northwest Laboratories, 1994, Richland, Washington.

Vogt, E. C., 1996, Letter to J. E. Mecca, "Completion of Dose Estimate for PFP Stabilization Operations", 9652258, from Westinghouse Hanford Company, Richland, Washington, dated May 17, 1996.

WHC $^{\text {a }}, 1988$, Nuclear Criticality Safety Manual, HNF-CM-4-29, Fluor Daniel Hanford Company, Richland, Washington.

WHC, 1989, Engineering Practices Guidelines, WHC-IP-1026, Westinghouse Hanford Company, Richland, Washington.

WHC, 1990, WHC Occupational ALARA Program, WHC-IP-1043, Westinghouse Hanford Company, Richland, Washington.

WHC, 1991, Radiological Design Guide, WHC-SD-GN-DGS-30011, Westinghouse Hanford Company, Richland, Washington. 
WHC, 1992a, Drafting Standards Manual, WHC-CM-6-3, Westinghouse Hanford Company, Richland, Washington.

WHC $^{\mathrm{a}}$, 1992b, Fire Protection Program Manual, HNF-CM-4-41, Fluor Daniel Hanford Company, Richland, Washington.

WHC $^{\mathrm{a}}$, 1992c, Industrial Hygiene Manual, HNF-CM-4-40, Fluor Daniel Hanford Company, Richland, Washington.

WHC, 1992d, Plutonium Finishing Plant Operating Specification for Storage of Special Nuclear Material, WHC-OSD-Z-184-00013, Westinghouse Hanford Company, Richland, Washington.

WHC $^{\mathrm{a}}$, 1992e, Safety Analysis Manual, HNF-CM-4-46, Fluor Daniel Hanford Company, Richland, Washington.

WHC $^{\mathrm{a}}$, 1993, Environmental Compliance Manual, HNF-CM-7-5, Fluor Daniel Hanford Company, Richland, Washington.

WHC, 1994a, Plutonium Finishing Plant Essential and Support Drawing List, WHC-SD-CP-TI125, Westinghouse Hanford Company, Richland, Washington.

WHC, 1994b, Plutonium Finishing Plant Operational Safety Requirements, WHC-SD-CP-OSR010, Westinghouse Hanford Company, Richland, Washington.

WHC, 1994c, Plutonium Finishing Plant Standards/Requirements Identification Document, WHCSD-MP-SRID-003, Westinghouse Hanford Company, Richland, Washington.

WHC ${ }^{\text {a }}$ 1994d, Standard Engineering Practices, HNF-CM-6-1, Fluor Daniel Hanford Company, Richland, Washington.

WHC, 1995a, Component Identifying Standard for the PFP, WHC-SD-CP-RD-024, Westinghouse Hanford Company, Richland Washington.

WHC, 1995b, Plutonium Finishing Plant Final Safety Analysis Report, WHC-SD-CP-SAR-021, Rev. 0, Westinghouse Hanford Company, Richland, Washington.

WHC, 1995c, Safety Manual, HNF-CM-1-10, Fluor Daniel Hanford Company, Richland, Washington.

WHC, 1996a, 94-1 Stabilization Project Vulnerability Risk Analysis, WHC-96-00015, Westinghouse Hanford Company, January 1996, Richland, Washington. 
WHC, 1996b, DNFSB Recommendation 94-1 Hanford Site Integrated Stabilization Management Plan, WHC-EP-0853, Revision 2, March 1996, Westinghouse Hanford Company, Richland, Washington.

WHC $^{\mathrm{a}}$, 1996c, Industrial Hygiene Manual , HNF-CM-1-11, Fluor Daniel Hanford Company, Richland, Washington.

WHC, 1996d, Location Assessment for the Plutonium Stabilization and Handling Process, WHC-SD-CP-TI-202, Westinghouse Hanford Company, Richland, Washington.

WHC, 1996e, PFP Standards/Requirements Identification Document , WHC-SD-MP-SRID-003, Westinghouse Hanford Company, Richland, Washington.

WHC $^{a}$, 1996f, Quality Assurance , HNF-CM-4-2, Fluor Daniel Hanford Company, Richland, Washington.

a All Hanford site-wide manuals were changed to an initial designator of "HNF" beginning in December 1996, and are shown that way for ease of retrieval regardless of actual manual issue date. 


\section{SELECTED ACRONYMS AND ABBREVIATIONS}

$\begin{array}{ll}\text { ALARA } & \text { As Low As Reasonably Achievable } \\ \text { BNFL } & \text { British Nuclear Fuels Limited, Incorporated } \\ \text { CAM } & \text { Continuous Air Monitor } \\ \text { CCTV } & \text { Closed Circuit Television } \\ \text { C/S } & \text { Containment and Surveillance } \\ \text { CSER } & \text { Criticality Safety Evaluation Report } \\ \text { DA } & \text { Destructive Assay } \\ \text { DBE } & \text { Design Basis Earthquake } \\ \text { DNFSB } & \text { Defense Nuclear Facilities Safety Board } \\ \text { DOE } & \text { Department of Energy } \\ \text { FSAR } & \text { Final Safety Analysis Report } \\ \text { HEPA } & \text { High Efficiency Particulate Air } \\ \text { HNF } & \text { Document designator for Hanford after October 1, 1996 } \\ \text { IAEA } & \text { International Atomic Energy Agency } \\ \text { LAN } & \text { Local Area Network } \\ \text { MAA } & \text { Material Access Area } \\ \text { NDA } & \text { Non-destructive Assay } \\ \text { NOC } & \text { Notice of Construction } \\ \text { OSR } & \text { Operational Safety Requirements } \\ \text { PAX } & \text { Private Automatic Exchange } \\ \text { PFP } & \text { Plutonium Finishing Plant } \\ \text { PIV } & \text { Periodic Inventory Verification } \\ \text { PPE } & \text { Personal Protective Equipment } \\ \text { Pu } & \text { Plutonium } \\ \text { PuSH } & \text { Plutonium Stabilization and Handling (Project W-460) } \\ \text { PVMP } & \text { Plutonium Vulnerability Management Plan } \\ \text { SISMP } & \text { Site Integrated Stabilization Management Plan } \\ \text { SNM } & \text { Special Nuclear Material } \\ \text { SPS } & \text { Stabilization and Packaging System } \\ \text { VSIS } & \text { Vault Safety and Inventory System } \\ \text { WHC } & \text { Westinghouse Hanford Company } \\ & \end{array}$




\section{APPENDIX A}

\section{Background Information about 2736-Z Complex Ventilation}

The 2736-Z Storage/Support Complex is a standalone operating area with its own HVAC systems. Ventilation is on a "once through" basis except for small-volume recycle of room air to supply laboratory refrigeration air-conditioning systems and for the 2736-ZB Building.

Within the 2736-Z complex, ventilation zones conform to standard designations (they are reversed in the other PFP buildings). Zone 1 designates the area having the highest potential for contamination (e.g., gloveboxes), and Zone 4 designates areas where contamination is not normally present.

Redundant supply fans in room 602 of the 2736-ZB Building assure that supply ventilation air is provided to the facilities for personnel comfort, process ventilation, contamination control, and for equipment and/or other cooling needs during supply system component failure or scheduled maintenance. Redundant operating exhaust fans (2736-ZA and 2736-ZB) are provided to maintain desired zone pressures and exhaust flows during component failure and/or maintenance.

The 2736-ZA Building, approximately $5 \mathrm{ft}$ west of the 2736-Z Building, consists of two rooms. Room 1 originally housed a diesel generator that provided backup power for operation of the EF-1-1 and EF-1-2 exhaust fans and associated instrumentation and controls, CAMs, a stack sampler, and an instrument air compressor, which now are housed in Room 2. These exhaust fans and other equipment in Room 2 would now be supplied with backup power from the backup diesel generators in the $2721-Z$ Building. Ventilation supply air for Room 2 is normally provided by in-leakage; however, in the event that Room 2 air temperature is greater than or equal to $35 \mathrm{C}\left(95^{\circ}\right.$ F), a temperature controller activates a motor controlled damper that allows filtered room air to be exhausted to the atmosphere through two stages of HEPA filtration by exhaust fans EF-1-1/EF-1-2. Should the room temperature increase to greater than or equal to $41 \mathrm{C}\left(105^{\circ} \mathrm{F}\right)$, the temperature controller will activate another motor controlled damper that allows additional filtered room air to be exhausted to the atmosphere through two stages of HEPA filtration by the exhaust fans EF-1-1/EF-1-2. Room air intake for the exhaust system, through either F-3-1 or F-3-2, allows filtered outside air to be drawn into the room. Electric heaters with temperature controls provide winter heating. Supply and exhaust ventilation for Room 1 is provided by wall louvers.

Ventilation air for the 2736-ZB Building is supplied by two systems. One system provides conditioned air (steam heated or refrigeration cooled and filtered) by using two supply fans, SF-1 and SF-2, located in room 602 of the 2736-ZB Building. Each fan has the capacity to provide 250 $\mathrm{m}^{3} / \mathrm{min}\left(8800 \mathrm{fr}^{3} / \mathrm{min}\right)$ of supply air for distribution to all areas of the building except that portion housing the NDA laboratory. Normal supply air ventilation requirements are provided by one operating fan with the other on standby. The fan distributes $75 \mathrm{~m}^{3} / \mathrm{min}(2600 \mathrm{ft} / \mathrm{min})$ to ventilation Zone 4 areas (e.g., lunchroom, offices, restrooms), with the remainder to ventilation Zone- 2 areas. Approximately $80 \%$ of the air supplied to Zone 4 is recycled to the supply system. 
Air supplied to Zone 4 restrooms is exhausted to the atmosphere by exhaust fan EF-3. Air is supplied to the repackaging glovebox in Room 636 (Zone 1) from the dry-air system discussed in Section 5.4.3.

Exhaust air from the repackaging room and glovebox access hoods is filtered through a single-stage HEPA filter (two discharge ports, each filtered). Glovebox exhaust is through a HEPA filter installed on the outlet. These filtered exhausts, together with Zone 2 exhaust air; vacuum-pump exhaust from room air sampling; and exhaust air from the 2736-ZB Building, room 600 (Zone 3), which houses the ventilation exhaust fans EF-1 and EF-2, HEPA filters, etc., are combined, filtered through two additional stages of HEPA filtration, and discharged to the atmosphere through the $8.4 \mathrm{~m}$ ( $27 \mathrm{ft} 7 \mathrm{in}$.)-tall $296-\mathrm{Z}-5$ stack. One exhaust fan (EF-1 or EF-2) provides the necessary exhaust ventilation flow (approximately $200 \mathrm{~m}^{3} / \mathrm{min}\left(7200 \mathrm{ft}^{3} / \mathrm{min}\right)$ with the other on standby. Redundant HEPA filtration is provided by four filter banks, two in parallel operation and two on standby. Stack discharge air is continuously sampled and monitored.

A heat exchanger system, consisting of two heat transfer coils, a pump, and interconnecting pipes filled with ethylene glycol, is used for recovery of heat/cold from the 2736-ZB ventilation exhaust. A heat transfer coil upstream of the EF-1/EF-2 exhaust fans is heated or cooled by the exhaust flow. When the outside air temperature is below $20 \mathrm{C}\left(68^{\circ} \mathrm{F}\right)$ or above $27 \mathrm{C}\left(80^{\circ} \mathrm{F}\right)$, the ethylene glycol is recirculated to the preheater/precooler coil, located in the air supply duct upstream of the steam heater and the refrigeration unit, to provide preheating/precooling to conserve energy.

The second ventilation supply system provides filtered, conditioned air to the NDA laboratory section of Building 2736-ZB with supply fans SF-3 and SF-4 (one operating, one on standby) at a flow rate of $180 \mathrm{~m}^{3} / \mathrm{min}(6300 \mathrm{ft} / \mathrm{min})$. The supply air is maintained at the required temperature by electric heating in winter and refrigeration cooling during the warmer seasons. Supply air is distributed to the NDA areas through supply ducts and ceiling diffusers.

Exhaust air is collected by three exhaust ducts, each provided with a single stage of HEPA filtration. These filtered exhaust flows are combined, filtered through two additional stages of HEPA filtration, and recycled to the NDA supply system by fans RF-1 and RF-2. Recycled air at approximately $11 \mathrm{~m}^{3} / \mathrm{min}\left(400 \mathrm{ft}^{3} / \mathrm{min}\right)$ is diverted to provide supply air for the mechanical equipment room (Room 600). Redundant HEPA filtration is provided by four filter banks, two in parallel operation and two on standby. The recycled air is continuously sampled and monitored for radioactive content. If radioactive content exceeds the allowable limit for breathing air, the ventilation recycle exhaust air is diverted for discharge to the atmosphere through the $296-\mathrm{Z}-5$ stack. The NDA ventilation supply and exhaust now becomes a once-through system until the air monitor indicates that recycling of exhaust air can be resumed.

The NDA laboratory is classified as a ventilation Zone 2 with the pressure maintained at $-62.3 \mathrm{~Pa}$ $(-0.25$ in) w.g. A programmable controller located in Room 602 controls the dampers, supply/exhaust fans, and the heating/cooling of the laboratory. Loss of pressure control, temperature control, loss of a supply or exhaust fan, and other trouble situations are alarmed in 
the 234-5Z Building ventilation control room (Room 321), which is attended at all times. The operator can assume manual operation of the system to provide the necessary corrective action. 


\section{APPENDIX B \\ PERFORMANCE SPECIFICATIONS \\ FOR STABILIZATION AND PACKAGING SYSTEM}

\section{A Performance Characteristics}

The PuSAP contract is intended to provide an SPS unit for Hanford which will be very similar to the prototype unit now in design for Building 707 at RFETS. This appendix contains requirements for the Hanford unit. For consistency with the PuSAP contract, there are item numbers at the left margin which correspond to item numbers in the "System Specification for the Plutonium Stabilization and Packaging System" document for the prototype. Many items refer to a specific paragraph in the PuSAP contract. Technical requirements were in many cases slightly modified for Hanford's conditions and unique situation.

At the end of this appendix, a list of applicable requirements documents is included which parallels the list in the prototype System Specification. In case of conflict between specific items in an applicable requirements document and this appendix, the appendix will govern the project.

\section{A.1 Stabilization and Packaging System Performance}

SPS-1 System output of stabilized and packaged oxide shall be a minimum of two (2) 3013 packages to be stabilized per 2-shift day, plus four batches of material to be repackaged only. For throughput, assume that four incoming containers of plutonium oxide will be combined into one 3013 package. This means that the $\mathrm{Pu}$ SPS will be designed to handle a minimum of 18 incoming containers on one shift ( 16 containing oxide to be stabilized plus 2 convenience containers of oxide to be packaged only), resulting in the completion of six 3013 packages by the end of the next shift.

(DE-AC03-96SF20948, Attachment II, Section 4.1.4)

NOTE: Should the system be manned on day shift only, process operations (energized furnaces, welding, etc.) would occur during one 8 hour shift with furnace cool down, incoming and outgoing material staging, and routine maintenance on back shift.

SPS-2 SPS design shall minimize waste generation during operation and maintenance.

(DE-AC03-96SF20948, Attachment II, Section 4.1.4)

SPS-3 The SPS shall be capable of maintaining nuclear material control and accountability of process materials and waste streams which are part of, or generated by, operations within the system.

(DE-AC03-96SF20948, Attachment II, Section 4.2.7) 
SPS-4 The SPS shall be capable of consistent, successive operation through the wall of a contaminated glovebox.

(DE-AC03-96SF20948, Attachment II, Section 4.2.10)

SPS-5 The design of the SPS handling and processing equipment shall consider the pyrophoric and chemical reactivity of actinides.

(DE-AC03-96SF20948, Attachment II, Section 3.1.3)

SPS-6 The design of the SPS shall take into consideration hazards associated with plutonium oxide containing adsorbed water.

(DE-AC03-96SF20948, Attachment II, Section 3.1.4)

SPS-7 Provision shall be made for handling fine powders to avoid dissemination of significant quantities in system confinement enclosures and the spread of contamination through associated ventilation duct work.

(DE-AC03-96SF20948, Attachment II, Section 3.1.4 \& 4.2.4)

SPS-8 The SPS shall be designed to meet safety requirements for Performance Category3 and System Group II (e.g., equipment must maintain structural and pressure boundary integrity but need not remain functional during and after a natural phenomena event).

(DE-AC03-96SF20948, Attachment II, Section 4.1.2.2)

SPS-9 All structures, systems and components shall be designed to resist applicable loading including dead weight, operating (thermal, vibration, live loads, and environmental loads, as applicable) and seismic hazard loading. Provisions of DOE-STD-1020-94 shall be used for application of loads due to seismic hazards, except that a ductility factor of 1.0 shall be used and design stresses shall not exceed code allowables.

Load combination shall be analyzed per the methods and DBE used in the PFP FSAR. The dynamic approach shall be used for seismic analysis of the SPS per DOE-STD-1020-94. The calculated forces shall then be applied to the system or equipment statically in order to estimate the demand.

(Similar to DE-AC03-96SF20948, Attachment II, Sections 4.1.2.1, 4.1.2.3 and 4.1.2.4)

SPS-10 "Safety Class" and "Safety Significant" equipment and components shall be installed in accordance with

(DE-AC03-96SF20948, Attachment II, Appendix B, page 36)

SPS-11 Pu SPS design shall accommodate fixed positions for retaining of SNM within the system during unattended periods. 


\section{A.2 Receipt of Nuclear Material}

RA-1 The SPS shall provide capability for the receipt of existing containers into a receipt glovebox. The majority of containers shall be accommodated via inlet sphincters, with airlock or bag-in capability of sufficient size to accept the largest storage container indicated by PFP as needing to be unloaded in the SPS.

(DE-AC03-96SF20948, Attachment II, Section 4.2.2)

RA-4 For material control and accountability, the Pu SPS shall process (as data) all information on labels for incoming storage packages, to supplement the limited nuclear information provided by the Container Assay Monitor. This information shall be maintained in data storage in the process control computer, and coupled with 3013 package identification as the material is processed through the SPS.

RA-5 The Receipt Area shall provide capability of receiving existing containers manually or via a hoist.

RA-6 The Receipt Area shall provide support services to allow detection of surface contamination within a just opened outer container. (The detection instrumentation for surface contamination is Government Furnished Equipment).

\section{A.3 Preparation of Material for Stabilization}

MPA-1 Capabilities shall be included for decontamination and unloading of existing packages, waste stream handling, and accountability of process materials and waste streams.

(DE-AC03-96SF20948, Attachment II, Section 4.2.2)

MPA-5 Capability shall be provided for collection and removal of extraneous packaging materials associated with incoming containers.

(Similar to DE-AC03-96SF20948, Attachment II, Section 3.1.1)

MPA-6 The system shall have the capability for opening sealed 3013 packages for restabilization and repackaging, as necessary, or if the container closure does not meet the design requirements.

MPA-7 The SPS shall have capability to stabilize small pieces of plutonium metal $(<100$ grams) within a batch tray of oxide.

(Similar to DE-AC03-96SF20948, Attachment II, Sections 3.1.3 \& 3.1.4)

MPA-8 Some of the material to be stabilized is non-homogeneous and may be too coarse to pass through a screen prior to thermal stabilization. All material constrained by the screening process shall be removed and clumped oxide shall be broken down or pulverized. Coarse materials may consist of components such as 
ceramics, graphite, iron or stainless steel hardware (fasteners), plutonium metal, and clumps or chunks of oxide. Working space within the Material Receipt or Material Preparation Area shall be provided to house size reduction and blending equipment for this use, with the ability to transport trays to the area either prior or subsequent to stabilization. The size reduction and blending equipment for this purpose shall be provided as Government Furnished Equipment.

(Similar to DE-AC03-96SF20948, Attachment II, Section 3.1.4)

MPA-10 The handling equipment shall allow for visual inspection of the material prior to and after stabilization.

(DE-AC03-96SF20948, Attachment II, Section 3.1.4)

MPA-11 The container compactor must be able to compact the incoming inner site container/site convenience can (crimped "food pack" or slip-lid containers).

MPA-12 The compacted height of incoming containers to be disposed of shall not exceed $2 \frac{1}{2}$-in.

MPA-13 The container compactor shall be interlocked to require local two-handed activation from within the adjacent glovebox gloves, to prevent operation when an operator's hands are too close to the equipment.

MPA-14 The container compactor shall have a compaction cycle of less than five minutes with a maximum noise rating which would not require hearing protection for workers in the room.

MPA-15 The SPS shall provide capability for contained dispensing of plutonium oxide from incoming containers into furnace trays.

MPA-16 Capability shall be provided within the SPS for automated monitoring to prevent overfilling of a furnace tray with material to be stabilized, limiting both weight and level of material in the tray. A vibrator may be useful to keep the material fairly level.

\section{A.4 Transport of Containers within the Glovebox System}

TA-1 Automated transport of incoming convenience cans shall be provided from the beginning of the Material Preparation Area to the Tipping/Dispense/Fill Area, minimizing the potential for spillage while avoiding the furnaces.

TA-2 The SPS shall be capable of automated transport of open trays of plutonium oxide from the Material Preparation Area, to/from the Furnace Area, to/from the LOI Test Area, and to the Tipping/Dispense/Fill Area. During this transfer, the 
powder in the tray must remain in level uniform layer, and the potential for spillage minimized.

The SPS shall be capable of automated transport of all 3013 package components within the glovebox system in appropriate areas, including reversal to allow rework in the Material Preparation Area.

TA-3 Automated pickup and placement of cans and trays must be accurate within an estimated $\pm 1 / 4 "$.

TA-4 Remote visual monitoring capability of automated can and tray transport in the Transport Areas shall be provided, if physical barriers cannot satisfy mass limits for criticality safety.

\section{A.5 Thermal Stabilization via Furnaces}

FURN-1 Thermal stabilization of the plutonium oxide shall be accomplished by maintaining the oxide at $1000 \pm 50 \mathrm{C}$ in an oxidizing atmosphere for a minimum of two hours.

(DE-AC03-96SF20948, Attachment II, Section 4.2.5)

FURN-2 The furnaces shall operate in an oxidizing atmosphere with a gas having less than $1000 \mathrm{ppm}$ moisture. The flow of supplied gases shall be regulated to between 0.5 and $10.0 \mathrm{scfm}$ with control to $\pm 0.1 \mathrm{scfm}$. Filtration shall be required to assure no contamination of the material being stabilized. The exhaust from the furnaces shall be discharged directly to the ventilation system.

(DE-AC03-96SF20948, Attachment II, Section 4.2.5)

FURN-3 The furnaces shall be capable of operation inside a glovebox.

(DE-AC03-96SF20948, Attachment II, Section 4.2.5)

FURN-4 The maximum temperature of the outer shell of the furnace shall not exceed 50C. (DE-AC03-96SF20948, Attachment II, Section 4.2.5 and Appendix B, page 41)

FURN-5 The controller for the furnace shall be located outside the glovebox and shall include a display of the furnace temperature. The furnace temperature shall also be continuously recorded by chart and by a data logger. The furnace shall be able to operate continuously for up to 8 hours at $1000 \pm 50 \mathrm{C}$ in an oxidizing atmosphere.

(DE-AC03-96SF20948, Attachment II, Section 4.2.5, and Appendix B, page 42)

FURN-6 Furnaces shall have the capacity to limit heating and cool down rate, and to provide hold times at different temperatures in order to allow operational programming of furnace cycles.

(Similar to DE-AC03-96SF20948, Attachment II, Section 4.2.5) 
FURN-7 Each furnace shall have the capability of stabilizing two full batches of plutonium oxide simultaneously while maintaining a critically safe geometry.

\section{A.6 Testing of Stabilized Materials for Moisture / Volatiles Content}

LOI-1 The SPS shall include an in line capability for determining the moisture / volatile content of a representative batch sample by heating the sample in an oxidizing atmosphere to a temperature of $1000-0 /+50 \mathrm{C}$ for at least one hours or via equivalent ThermoGravimetric Analysis.

(Similar to DE-AC03-96SF20948, Attachment II, Section 4.2.5)

LOI-2 The plutonium oxide shall be thermally stabilized to less than 0.5 percent loss on ignition (LOI); the SPS shall have the capability to retain this characteristic through final packaging.

(DE-AC03-96SF20948, Attachment II, Section 4.2.5)

LOI-3 An adjustable temperature indicator / alarm shall be provided for the batch furnaces and the LOI/TGA furnace, to measure sample temperature and signal various operational temperatures.

LOI-4 A dessicator and a balance for analytical-quality weights shall be provided for holding of LOI samples until final weighing is completed.

LOI-5 All volatile materials associated with the convenience container shall be considered in the LOI measurement for plutonium oxides.

(DE-AC03-96SF20948, Attachment II, Section 4.2.6.5)

\section{A.7 Filling of Convenience Containers}

TFA-1 Movement of furnace trays from the batch furnaces into a dispensing area shall be automated, with capability for manual positioning of trays if required for recovery of a mechanical failure.

TFA-4 A balance for weighing of filled convenience cans shall be provided, with 4-place accuracy .

TFA-7 Provision shall be made to allow filling the convenience container with oxides that are either free flowing powders or agglomerated chunky material.

(DE-AC03-96SF20948, Attachment II, Section 4.2.6.5) 


\section{A.8 Packaging in Intermediate Can}

CWCI-1 In the can weigh/ cap insertion area, all movements of convenience cans, and insertion of the convenience can and bung into an inner can shall be automated.

Provisions shall be made for access to this area in case of mechanical malfunction, with a planned recovery mechanism available in case of incorrect bung insertion

ICHA-1 In the inner can handling area, all movements of packaging components shall be automated.

ICHA-2 The rotating sphincter seal shall be designed for ease of maintenance and with relatively large tolerance for misfeeds of packaging components.

\section{A.9 Leak Testing and Packaging in Outer Can}

OWM-1 Provide helium leak detectors for testing the seal on both the inner container and the outer container. The lead detector system(s) shall be designed to:

1) Have a sensitivity twice as great as the minimum leak. DOE-STD-3013-96 required the maximum leak to be less than or equal to $1 \times 10^{7}$ standard cubic centimeters of gas per second across a pressure gradient of 1.0 atmospheres. This is equivalent to $4 \times 10^{-12}$ moles of air or helium per second.

2) Minimize the potential for radioactive contamination should a container leak

3) Prevent pump oil from being drawn into the glovebox

4) The location of the leak detectors shall take into consideration the potential for a false leak indication should the atmosphere outside the container become contaminated with helium.

(DE-AC03-96SF20948, Attachment II, Section 4.2.8)

OWM-2 All functions of the outer can weld and monitoring area shall be automated: leak testing of the inner can weld, welding of the outer can assembly, testing of the outer can for removable surface contamination, leak testing of the outer can weld, receipt of sealed inner cans into empty outer cans, movement of the outer can assembly within the Outer Can Weld and Monitoring Area, and movement of the completed storage package into the Lag Storage Trolley. 


\section{B Specialty Component Specifications}

\section{B.1 Gloveboxes}

BOX-1 Construction and configuration of system gloveboxes shall comply with DOE 6430.1A, Sections 1161-1 and 1161-2, and with the Guidelines for Gloveboxes, American Glovebox Society.

(DE-AC03-96SF20948, Attachment II, Appendix B, page 36)

BOX-2 Gloveboxes and hood shells shall be at least 7 gauge Type 304 stainless steel. All internal structural members and supports and exterior stands shall be 304 stainless steel. Determination of glovebox skin thickness shall consider structural issues for preventing glovebox floor warpage during Pu SPS operations

(DE-AC03-96SF20948, Attachment II, Appendix B, page 38)

BOX-3 Windows located on top of the gloveboxes for lighting shall be $1 / 4$ inch wire glass. All other light and viewing windows shall be safety plate glass.

(DE-AC03-96SF20948, Attachment II, Appendix B, page 38)

BOX-4 Glove rings/ports shall be constructed to provide a means to install airtight flexible gloves for access and manipulation inside the enclosure. All glove ports/rings shall be of a push-through type. Gloves shall be provided for all glove ports. Plugs shall be provided for $80 \%$ of glove ports.

(DE-AC03-96SF20948, Attachment II, Appendix B, page 38)

BOX-5 A goal, which should be followed when possible, is to provide planned storage fixtures inside gloveboxes and hoods for tools and equipment parts. However, items welded directly to the gloveboxes should be kept to a minimum to facilitate decontamination and operational flexibility.

(DE-AC03-96SF20948, Attachment II, Appendix, B, page 38)

BOX-6 Continuous butt welds are required for the glovebox skin and should be located away from corners or edges. Whenever possible, gloveboxes shall be welded to one another, to entry cabinets, and to airlocks. Gloveboxes without stands shall fit well with the floor but high grade caulking is acceptable to seal box or storage cabinet to floor covering.

(DE-AC03-96SF20948, Attachment II, Appendix B, page 39)

BOX-7 Gloveboxes shall be provided with gaslocks to pass equipment from one glovebox to another. Each gaslock shall be fabricated from stainless steel, finished the same as the glovebox and equipped with a transfer tray.

Two general types of gaslocks will be provided. One will be used between gloveboxes having different atmospheres (inerted vs. dry air). It will have 
provisions to allow the gaslock to be purged and backfilled with the appropriate atmosphere to minimize dilution of the atmosphere in the inerted gloveboxes.

The other type gaslock will be between gloveboxes having the same atmosphere. These gaslocks provide barriers for the spread of contamination. No provisions for backfilling these gaslocks will be necessary. However, vents to equalize pressure between the gaslock and the adjoining gloveboxes will be required to act as "vacuum breakers". The gaslocks shall have piping connections to the vacuum system and dry air or inert atmosphere supply system, as appropriate, for evacuation and backfilling.

(DE-AC03-96SF20948, Attachment II, Appendix B, page 39)

BOX-8 All glovebox exterior surfaces that are visible and accessible should have a uniform appearance as near the interior box finish as possible. Where possible the fabricators finish should be able to be duplicated or matched in the field where assembly welds are matched to maintain a uniform appearance. Surfaces of structural members inside gloveboxes shall correspond to the shell finish. Machined surfaces shall have a 64 to 125 AA finish and rounded corners. Outside structural members shall have a mill finish, aesthetically similar to the exterior shell finish.

(DE-AC03-96SF20948, Attachment II, Appendix B, page 40)

BOX-9 All process and service piping as well as electrical and instrument lines shall enter or exit gloveboxes by means of pass-through connectors that do not compromise leak tightness (e.g., welding, low-permeability gaskets, or potting).

(DE-AC03-96SF20948, Attachment II, Appendix B, Page 41)

BOX-10 All gas supply lines shall be filtered before they pass through the glovebox shells in order to prevent migration of contamination into the clean supply lines.

(DE-AC03-96SF20948, Attachment II, Appendix B, page 41)

BOX-11 After installation, glovebox openings shall be blanked off and the gloveboxes shall be tested for overall box leak tightness to $1 \times 10^{2} \mathrm{~atm}-\mathrm{cc} / \mathrm{sec}$ of helium or equivalent.

(DE-AC03-96SF20948, Attachment II, Appendix B, page 41)

BOX-12 If a glovebox requires a cooling system, heat exchangers will be sized to meet the needs of individual glovebox loads. Limit the number of different sizes to help control spare parts. A sensor can monitor the glovebox temperature and, via controller, regulate the coolant flow to the heat exchanger. Water is an acceptable coolant fluid. If water is used as a coolant, provisions shall be made to prevent leakage of water into the glovebox based on criticality concerns...

(DE-AC03-96SF20948, Attachment II, Appendix B, page 41) 
BOX-14 Utilities (e.g., water, air, gas) serving gloveboxes shall be provided with remote shutoff or isolation valves.

(DE-AC03-96SF20948, Attachment II, Appendix B, page 42)

BOX-15 Airlock and gaslock doors shall be interlocked to prevent cycling if an item such as a human hand is in an accessible and operational gloveport.

BOX-16 Pneumatic operators within a glovebox shall use dry air or nitrogen.

\section{B.2 Transport of Completed Packages}

LST-1 Each Lag Storage Trolley will be sized to handle two storage packages, set vertically in a shielding block. The trolley shall be designed to keep the center of gravity low enough to minimize any tipping hazard. The block shall be designed to maintain critically safe geometry during movement of one package while another remains in the shielding block.

LST-2 Interlocks will be provided to prevent the Lag Storage Trolley from disengaging from the Pu SPS when being filled or awaiting filling with completed storage packages.

LST-3 A total of four Lag Storage Trolley will be provided to permit staging of filled packages.

LST-4 Lag Storage Trolleys will be shielded to minimize occupational exposure to ionizing radiation (ALARA).

\section{B.3 Furnace Trays}

FT-1 Any single container, crucible, or ladle containing or transporting SNM in the glovebox systems shall be limited to a maximum of $4.9 \mathrm{~kg}^{239} \mathrm{Pu}$ as oxide of bulk density between 1.5 and $6 \mathrm{~g} / \mathrm{cc}$.

(DE-AC03-96SF20948, Attachment II, Appendix B, page 37)

FT-3 Furnace trays shall be sized to contain the quantity of plutonium oxide required in FT-1, at a maximum depth of 1.5-in at an estimated density of $2 \mathrm{gm} / \mathrm{cc}$ while leaving about 0.5 inches of freeboard between the top of the oxide layer and the lip of the tray.

FT-4 Furnace trays shall be capable of withstanding repeated heating and cooling between ambient temperature and $1,000 \mathrm{C}$ without excessive oxidation, distortion, or degradation of the tray identifier technique. 


\section{B.4 Atmosphere in Enclosures}

HGA-2 The design for the interface between the SPS and the ventilation system shall prevent backflow into to the facility ventilation system.

(DE-AC03-96SF20948, Attachment II, Section 4.1.3)

HGA-3 Gas supply lines shall contain HEPA inlet filtering or a backflow prevention device between the supply and the glovebox atmosphere to eliminate backflow of radiological contamination.

(Similar to DE-AC03-96SF20948, Attachment II, Section 4.1.3)

HGA-4 Glovebox exhaust lines shall contain HEPA filters to provide initial filtering prior to the process exhaust system. These filters are not included in the two stages of required testable HEPA filtration in the exhaust system.

(Similar to DE-AC03-96SF20948, Attachment II, Section 4.1.3)

HGA-5 Any hoods used in the SPS shall be designed to minimize the gas flow required to meet/maintain a minimum face velocity of $150 \mathrm{ft} / \mathrm{min}$.

(DE-AC03-96SF20948, Attachment II, Appendix B, page 36)

HGA-8 Differential pressures in the SPS shall be such that the flow of air through leakage in the confinement systems will always be from areas of lower contamination to areas of higher contamination, for example, from the general facility, to the SPS room, to the interior of the gloveboxes or hoods. Backflow of air from a more contaminated area to a lesser contaminated area shall be prohibited via filtration or backflow preventors.

(DE-AC03-96SF20948, Attachment II, Appendix B, page 41)

HGA-9 The exhaust exits from the gloveboxes shall have radial flow HEPA filtration. The ventilation supply shall include backflow dampers. HEPA filters in the supply and exhaust systems shall be located as close to the glovebox as practicable to minimize ductwork contamination.

(DE-AC03-96SF20948, Attachment II, Appendix B, page 42)

HGA-10 To prevent glovebox overpressurization, a means of rapidly exhausting the glovebox (e.g, dump valves or similar device) shall be provided on gloveboxes that have a potential pressure source.

(DE-AC03-96SF20948, Attachment II, Appendix B, page 42)

HGA-11 Gas inlets to the gloveboxes and furnaces shall preclude dispersal of plutonium oxide from open furnace trays. 


\section{B.5 Electrical Components Within Gloveboxes}

E-2 Associated electronics, controls, and power supplies shall be contained in cabinets mounted in a rack where possible.

(DE-AC03-96SF20948, Attachment II, Section 4.1.5)

E-3 All electrical connectors within gloveboxes shall be dust tight.

(DE-AC03-96SF20948, Attachment II, Section 4.1.5)

E-4 Electrical connectors at glovebox walls shall be plug-type disconnects.

(DE-AC03-96SF20948, Attachment II, Section 4.1.5)

E-6 Lighting fixtures for gloveboxes shall have illuminaries with baffles, or other devices, to diffuse light and to assure that the bulb is not visible to the operator's eye. The lighting interior and exterior to the glovebox shall provide a method for adjustment to minimize glare. The ease of viewing at working surfaces and points of operation shall be considered during the design of lighting for gloveboxes. A desirable lighting level at these locations is $50-60$ foot-candles.

(DE-AC03-96SF20948, Attachment II, Appendix B)

E-7 Fluorescent lighting with $110 \mathrm{~V}$ receptacles is preferred but other types may be used when necessary. Lights may be grouped with a common switch for a number of lights serving a hood or glovebox.

(DE-AC03-96SF20948, Attachment II, Appendix B)

E-8 Lighting fixtures shall be installed exterior to the gloveboxes to the extent practical to aid in maintenance of the fixtures.

(DE-AC03-96SF20948, Attachment II, Appendix B)

E-9 Electrical equipment and lighting shall be designed and installed to meet the requirements of NFPA 101.

\section{B.6 Seismic Considerations for Support Structures and Platforms}

SSP-1 All structures, systems and component supports associated with the design shall be designed ... per the criteria found in ref. 2.1.8.1 for the appropriate Performance Category of the SSC.

(DE-AC03-96SF20948, Attachment II, Section 4.1.2.1 and Appendix B)

SSP-2 All structures, systems and component supports associated with the design shall be constructed per the criteria found in ref. 2.1.8.1 for the appropriate Performance Category of the SSC.

(DE-AC03-96SF20948, Attachment Il, Section 4.1.2.1 and Appendix B) 
SSP-3 Existing systems and equipment which are to be used for the SPS either modified or unmodified, will be reviewed to ensure their capability to withstand applicable loading. Existing systems and equipment which are not going to be used for the SPS, and are left as is in the area of the project location, will be reviewed for seismic interaction affecting safety related SPS equipment.

(DE-AC03-96SF20948, Attachment II, Section 4.1.2.1)

SSP-4 Concrete anchorage will be designed using the guidelines of ACI-349, including commentary.

(DE-AC03-96SF20948, Attachment II, Section 4.1.2.1)

SSP-5 Equipment supports will be designed to avoid resonance resulting from the harmony between the natural frequency of the structure and the operating frequency of supported reciprocation or rotating equipment per DOE 6430.1A, section 0111-2.8.1.

(DE-AC03-96SF20948, Attachment II, Section 4.1.2.1)

SSP-6 All internal structural members and supports and exterior stands shall be constructed of 304 stainless steel.

(DE-AC03-96SF20948, Attachment II, Section 4.1.2.3)

SSP-7 Seismic loads for concrete anchorage of fixtures and equipment in the $2736-Z$ Complex shall be calculated using

(Similar to DE-AC03-96SF20948, Attachment II, Section 4.1.2.3)

SSP-8 Seismic decoupling shall be provided between the last stabilization process glovebox and the first packing process glovebox, which should accommodate axial movement (compression) and lateral movement during design basis seismic events.

\section{Safety Considerations}

\section{C.1 Industrial Safety}

SAFE-1 The SPS design shall protect workers sufficiently from hazards to ensure that workers can perform actions required during normal operations, anticipated operational occurrences, and postulated accidents.

(DE-AC03-96SF20948, Attachment II, Section 4.5.1)

SAFE-2 The design shall ensure prompt, safe shutdown in emergencies, and allow ready access to areas where manual corrective actions are required.

(DE-AC03-96SF20948, Attachment II, Section 4.5.1)

SAFE-3 The SPS design shall ensure that "Safety Class" components will continue to perform their functions during all normal operations and anticipated operational occurrences and during and after any postulated emergency or accident condition. Safety Class components or items shall continue to operate until appropriate 
corrective actions can be taken to bring the facility or system to a safe condition and the function of the Safety Class item is no longer required.

(DE-AC03-96SF20948, Attachment II, Section 4.5.1)

SAFE-4 The design of the gloveboxes and the equipment, or location of equipment, in the gloveboxes shall prevent pinch points and shall prohibit sharp corners and protrusions that can puncture glovebox gloves. ... All corners shall be smooth and rounded - minimum radius of about $5 / 8$ inches.

(DE-AC03-96SF20948, Attachment II, Appendix B)

SAFE-5 Include associated safety requirements and surveillance actions necessary to ensure the fail safe operation of the SPS in accordance with applicable IS\&H, NFPA, and OSHA requirements.

(DE-AC03-96SF20948, Attachment II, Section 4.5.1)

SAFE-6 Machine Guarding - Machinery and moving parts which are accessible to operators will be sufficiently guarded to prevent injury from inadvertent contact. Machine guards shall meet the requirements of 29 CFR 1910, Subpart O, Machinery and Machine Guarding, and including section 212, General Requirements for All Machines.

SAFE-7 Electrical Safety - All electrical components shall meet all local and site code requirements as well as those in 29 CFR 1910, Subpart S, Electrical Standards, and including sections 302 to 308, Design Standards for Electrical Systems.

SAFE-8 Lock Out/Tag Out Requirements - Potential sources of hazardous energy (i.e. electrical, hydraulic, high pressure lines, etc.) will have the capability to be locked out in accordance with 29 CFR 1910, Section 147, Control of Hazardous Energy Sources. The hardware to perform such lock outs will be consistent with the RFETS Safety and Health Practices Manual.

SAFE-9 Work Platforms and Work Surfaces - Work platforms and surfaces shall meet the requirements of 29 CFR 1910, Subpart O, Walking and Working Surfaces, and including section 23(c), Protection of Open Sided Floors, Platforms and Runways, and section 24, Fixed Industrial Stairs.

SAFE-10 Compressed Gases - The storage facilities and systems for compressed gases shall meet the requirements of 29 CFR 1910, Subpart M, Compressed Gases and Compressed Air Equipment, and all incorporated references.

As good engineering practice, fittings for the inert gases will be developed to ensure that compressed air or oxygen cylinders cannot be inadvertently connected to the systems which are used to inert glove boxes and enclosures. The use of compressed air to power pneumatic machinery in areas of the process where there is the potential for ignition of plutonium or other materials shall be minimized to the extent practical. 
SAFE-11 The installation of lasers in the system shall meet the requirements of ANSI Z136.1, Standard for Use of Lasers.

\section{C.2 Radiation Shielding Requirements}

RADP-5 Shielding shall be included in the design of the gloveboxes. Operator exposures shall be maintained ALARA with a goal of no more than 500 mrem per year to the whole body from the SPS. Measured or calculated exposures should include the logged time/dose for all processing steps in the SPS, including those performed both inside and outside the gloveboxes.

(DE-AC03-96SF20948, Attachment II, Sections 3.1.1)

RADP-6 In glovebox areas, stainless steel shall be used to shield gamma radiation and solid materials shall be used to shield neutron radiation. Any flammable shielding materials to be employed must be outside of the gloveboxes and encased in nonflammable materials. Windows shall use lead glass to shield gamma and neutron radiation.

(DE-AC03-96SF20948, Attachment II, Appendix B)

\section{C.3 Design for Nuclear Safety}

CRIT-1 Provisions shall be included in the design of the glovebox system to assure that the materials, as applicable, are always in a desirable geometry and array to prevent criticality. Geometric control of the material and array using administrative controls shall be allowed only if no other practical control method can be used.

CRIT-2 ...all glovebox criticality limits will be based on maintaining a system with moderation sufficient to represent operator's arms in the glovebox.

(DE-AC03-96SF20948, Attachment II, Appendix B)

CRIT-3 No water or other hydrogenous liquid sources will be supplied to a glovebox to ensure that no single breach of fluid containment, an anticipated event, will be available to flood the box or saturate the oxide trays. The equipment shall be designed to remain subcritical if flooded .

CRIT-4 Accurate (to about 10\%) measurement of container contents will be performed upon receipt of material introduced to the Pu SPS in the original container, to minimize the likelihood of inserting the wrong container into the system due to a simple paperwork or human error.

CRIT-5 All gloveboxes shall have designated, fixed locations with restraints for unit masses of plutonium, with at least 2" (in) edge-to-edge spacing between locations. The receipt area must accommodate up to four incoming material cans to make up batches from small cans. 
CRIT-7 Furnace tray racks shall EITHER be designed for a minimum of 6" (inches) edgeto-edge spacing (vertically) OR furnace tray racks shall not become flooded when designed for $\mathbf{4}$ or less trays, using any spacing. No more than one furnace tray shall be uncovered at any given time, ie., outside of a furnace without a lid.

CRIT-8 All plutonium cans and trays will be covered when not being processed (to preclude entrance of water during a DBE or fire.)

CRIT-9 All Pu SPS areas with plutonium will be designed such that the effects of a DBE will not result in more than two cans of metal making contact with each other.

CRIT-10 Engineered features will be provided to preclude water ingress into the furnaces during a DBE or other accident.

CRIT-14 Administrative and process controls shall limit the total amount of plutonium allowed in the SPS at any time, with process controls set to allow only the containers for a maximum of 4 batches (maximum $20 \mathrm{~kg}$ plutonium) within the system.

\section{SPS Process Control and Data Management}

\section{D.1 Process Control System}

PSC-1 Provide stabilization process equipment safety interlocks as required by the PSE for this project, followed by rigorous hazards analysis during detail design.

PSC-2 Monitor and control environmental conditions within the stabilization and packaging processes for radiological contamination and inert atmosphere integrity.

PSC-3 Obtain selected data inputs of stabilization and packaging process information, either by keypad entry or by reading data via bar code reader.

PSC-4 Control automatic operations within the stabilization and packaging processes.

PSC-5 Provide information from the stabilization and packaging processes to the Data Management System for site material control and accountability requirements and storage package certification requirements.

PPC-1 Balances shall be used to record the weight of material going into the inner containers, the weight of the loaded inner containers, the weight of the outer container, and the final weight of the loaded storage package. Each balance requires a minimum range of 0 to 1.5 times the maximum package weight in grams. Balances shall meet the requirements of DOE Order 5633.3B for accuracy 
and repeatability. Balances shall have the capability to interface with remote recording equipment.

(DE-AC03-96SF20948, Attachment II, Section 4.2.7)

PPC-7 Alarms and indicators shall be provided to alert operators of off normal situations. Alarms and indicators for manual work stations shall be both local and at the process control computer.

\section{D.2 Data Management System}

DMS-3 Provide data to support storage package certification requirements in 3013.

DMS-4 Provide system operational information, for trending equipment performance and use.

\section{D.3 Control and Data System Security}

SECR-1 Control system computer security is provided by password protection to the configuration software.

\section{E Construction Considerations}

\section{E.1 Site Construction Constraints}

PHYS-2 The dimensional limits for the largest single component (including packaging) that can be physically moved into 2736-ZB (due to door size and maneuvering limitations) are approximately $6^{\prime}-6^{\prime \prime}$ high by $5^{\prime}-6^{\prime \prime}$ wide by $8^{\prime}$ long.

\section{E.2 Protective Coatings and Cleaning}

COAT-1 After fabrication and inspections have been completed, all system components shall be thoroughly cleaned, descaled, and degreased. All surfaces shall be cleaned to remove such debris and contaminants as weld flux, oil, grease, shop dust, masking tape, cutting fluids, grinding residue and temporary markings. Cleaning may be accomplished by mechanical means, with non-halogenated solvents, or by using water, steam or non-halogenated detergent cleaning agents or any combination thereof. Caustic or acid cleaning shall not be used. Final wash and rinse shall be accomplished with potable water meeting the requirements of the Public Health Service Drinking Water Standards. Drying after final rinsing shall be accomplished using forced dry air. Compressed air used for drying shall be free of water and oil. 
COAT-2 No stainless steel surfaces, interior or exterior, shall be painted unless specifically called for in this specification. All unfinished carbon steel components of the equipment shall be thoroughly cleaned by sandblasting or pickling to remove all chemical contamination, mill scale, rust scale and rust and shall be painted with one coat of epoxy paint. No paint shall be applied within $1 / 2$ inch of field weld areas.

(DE-AC03-96SF20948, Attachment II, Section 4.7.3)

\section{E.3 System Quality Factors}

RAM-1 The SPS shall have a design life of 50 years. Material handling and processing equipment shall be designed for consistent and robust operations through the initial campaign ending approximately seven (7) years after startup. Periodic low volume operations shall be required for 7 to 50 years. Robust operation is defined as a ratio of operating time to maintenance (corrective and preventive) down time of greater than 100 . Consistent operation is defined as consecutive packaging operations using the same parameters with the same results and no system failures requiring major repair activities.

(DE-AC03-96SF20948, Attachment II, Section 4,2,10)

RAM-3 The system shall be easily maintainable as defined by the demonstrated replacement of critical wear parts within two hours. Critical wear parts are defined as any parts, critical to the operation of the Pu SPS, that are expected to require replacement or repair during the initial seven year campaign.

(DE-AC03-96SF20948, Attachment II, Section 4.2.10)

RAM-4 Any routine maintenance operation should generate no more waste than an equivalent normal shift operation.

(DE-AC03-96SF20948, Attachment II, Section 4.2.10)

RAM-5 Space shall be provided adjacent to all equipment and confinement systems to allow easy access for maintenance.

(DE-AC03-96SF20948, Attachment II, Section 4.2.10)

RAM-6 To the extent practical, equipment and components inside gloveboxes shall be maintainable from the exterior of the glovebox.

(DE-AC03-96SF20948, Attachment Il, Section 4.2.10)

RAM-7 The radiation shielding for gloveboxes should be designed to facilitate installation, removal, and decommissioning of Pu SPS equipment. 
RAM-8 An appropriate number of spares shall be provided for parts subject to wear or other deterioration that can credibly be predicted to require replacement at (preliminary) frequency of one year or less, and that are not readily available for procurement.

\section{E.4 Environmental Conditions}

ENVR-1 All equipment and associated components shall be designed to function at ground level elevations ranging from 0 to 8000 feet above sea level.

(DE-AC03-96SF20948, Attachment II, Section 4.1.5)

ENVR-3 Equipment located inside gloveboxes will be subjected to an inert nitrogen or helium gas environment: oxygen content 0 to 5 percent, temperature 55 to $100^{\circ} \mathrm{F}$, humidity $25 \%$ maximum.

\section{E.5 Materials of Construction}

MATL-1 Gasket materials shall be chosen as needed for low permeation, compatibility with low humidity, argon, and oil resistance if necessary.

(DE-AC03-96SF20948, Attachment II, Appendix B, page 38)

MATL-2 Inside special hardware shall be Type 300 series stainless steel, however, galling characteristics of special hardware with respect to 300 series stainless steels shall be evaluated. Commercial stainless steel hardware may be used outside the glovebox for handles and hinges.

(DE-AC03-96SF20948, Attachment II, Appendix B, page 38)

\section{E.6 Toxic Products and Formulations}

TOX-1 Asbestos or asbestos-bearing materials shall not be used.

(DOE 6430.1A, Section 1525-1)

TOX-2 Mercury or mercury-bearing materials shall not be used, except in the external, commercial fluorescent lighting on top of the gloveboxes.

TOX-3 Polychlorinated biphenyls (PCB) or PCB-bearing materials shall not be used.

TOX-4 Metallic lead, which may be used for radiation shielding purposes, shall be encapsulated. 
TOX-5 All materials installed or used in the SPS shall be used in accordance with OSHA Material Safety Data Sheets (MSDS) requirements in reference 29 CFR 1910, Subpart Z.

\section{E.7 Use of Standard and Commercial Parts}

PART-1 Include provisions in the quality system to assure that materials used or supplied are not counterfeit or otherwise of suspect origin. (Particular attention should be paid to high strength bolting materials (Grade 5 strength equivalent and higher), circuit breakers, pipe fittings, fuses, and electrical relays which have in the past been a concern to the DOE and its contractors).

PART-2 Mechanical fasteners may be of either US or metric standard dimensions, materials, and strengths.

PART-3 Electrical components shall be NEMA or equivalent. Motor control shall be IEC. Protective devices shall have Type 2 Coordination, as a minimum.

\section{E.8 Electromagnetic Radiation}

EMR-1 Non-destructive assay equipment shall be protected from electromagnetic radiation sources.

( DOE 6430.1A, Section 1300-10.3.3)

\section{E.9 Nameplates and Product Marking}

NAME-1 All equipment, controls, instruments, and panels included in the SPS shall have unique identification numbers. The equipment numbers shall be obtained from the site specific equipment numbering system and shown on the drawing.

(DE-AC03-96SF20948, Attachment II, Section 4.7.2)

NAME-2 .Provide a Master Equipment List containing the equipment ID numbers, description, part number, and specifications (e.g., range, set point, alarm point).

(DE-AC03-96SF20948, Attachment II, Section 4.7.2)

NAME-3 Comply with Hanford Site labeling standards.

(Similar to DE-AC03-96SF20948, Attachment II, Section 4.7.2) 


\section{E.10 Construction for Ease of Decontamination}

DECON-1 Crevices and sharp corners shall be eliminated from the glovebox design, including equipment installed in the glovebox, to prevent the accumulation of contaminated materials that are inaccessible for cleanup. The design of the glovebox and the installation of the equipment in the glovebox shall not create areas that are inaccessible for cleaning. ... Seals that can collect materials that cannot be removed shall be avoided.

(DE-AC03-96SF20948, Attachment II, Appendix B, page 36)

DECON-2 Gloveboxes shall have metal surfaces polished to a \#4 finish to promote contamination control and to provide for enhanced cleanup. The objective should be that all interior surfaces are smooth to facilitate cleaning and decontamination.

(DE-AC03-96SF20948, Attachment II, Appendix B, page 36)

DECON-3 Whenever practical, porous surfaces in the SPS process area should be sealed or provided with a surface liner to prevent entrapment of contamination to facilitate the cleanup of the process area.

DECON-4 Gloveboxes and large, heavy components should be provided with appropriate lifting lugs to facilitate dismantlement and decontamination activities

DECON-5 Where practical, equipment and gloveboxes subject to contamination should be designed for easy and effective decontamination and dismantlement. This enhances the effectiveness of the eventual decontamination, dismantlement, and relocation of process equipment.

\section{E.11 Human Factors Engineering}

HENG-1 Gloveboxes and hoods may be single wall construction with the main working surface 36 to 38 inches from the floor, where possible. The height and depth shall be determined to provide optimum orientation and access to the equipment in each enclosure.

(DE-AC03-96SF20948, Attachment II, Appendix B, page 38)

HENG-2 Internal supports shall be placed to minimize interference with normal operation and maintenance.

(DE-AC03-96SF20948, Attachment Il, Appendix B, page 38)

HENG-3 Human Dimensions Considerations - The dimensions of the human body shall be considered when selecting equipment and designing systems for use on the project. Equipment shall be arranged in a manner to provide easy access for operations, maintenance, and repair. Tools, platforms and other operator aids shall be 
provided as required. Equipment shall accommodate the fifth to ninety-fifth percentile of population.

HENG-4 Process Controls - The process control strategy developed should provide for centralized monitoring and a readily identifiable control hierarchy.

HENG-5 Process Controls - Operating procedures should provide clear, concise guidance for manual system operations under normal, abnormal, and emergency operating conditions.

HENG-6 Display Devices - The control system display must be designed to provide the operators with sufficient information to control the process, without compromising their ability to respond to upset conditions due to cognitive overload. Control panel layouts should permit easy access to controls and visual indications. Computer graphics screens should consider the use of color, contrast, and text size in formulating displays. Dynamic process data (process parameters, equipment status) should be readily interpreted, and abnormal conditions should be clearly identifiable to the operator.

HENG-7 Warning Indicators - It is essential that operators be advised of abnormal or potentially hazardous situations in a clear, concise and timely manner. Local and remote indication shall be included as appropriate to notify operators of process alarms. Local area and general building alarms shall alert all personnel in project areas of environmental hazards in accordance with established RFETS Standards and Health and Safety procedures.

HENG-8 Labeling - Equipment and instrumentation shall be appropriately labeled to permit proper identification during normal, abnormal, emergency and surveillance operations.

HENG-9 Handicap Access - Fire, criticality, and radiological hazards will require rapid evacuation of the project areas. Due to this constraint, access to the area by handicapped people will be restricted. Specific exemption from the Architectural Barriers Act, Public Law 90-480, shall be addressed in accordance with 41 CFR 101-19.6 during the design phase.

HENG-10 Environmental Conditions - The environmental conditions under which operation and control actions are performed affect the performance that may be expected of operators. To provide operators with conditions to support the proper execution of required tasks, ambient temperature, humidity, air flow, noise level, and illumination should be controlled within acceptable limits. Applicable limits for these parameters are specified in UCRL-15763, Human Factors Design Guidelines for Maintainability of Department of Energy Nuclear Facilities. 


\section{E.12 Quality Assurance Requirements}

QUAL-1 Design, fabrication, and procurement of equipment for the SPS shall meet the requirements of a Quality Assurance Program which meets the requirements of 10 CFR 830.120 and it's related Implementation Guide. The preferred standard for the quality assurance program to implement the quality assurance provisions of the rule is ASME NQA-1, QA Requirements for Nuclear Facilities

(DE-AC03-96SF20948, Attachment II, Sections 4.1.5 \& 4.6)

QUAL-2 Perform all work in accordance with the contract documents and ...ensure all work is in compliance with all quality and design requirements contained in the contract documents.

(DE-AC03-96SF20948, Attachment II, Section 4.6)

QUAL-3 Those Pu SPS systems, subsystems, and portions of subsystems required to perform an identified safety function are classified as (project) Quality Level 1 and will be engineered and designed in accordance with applicable BNFL procedures for Quality Level 1 equipment.

(Quality Assurance Plan, Procedure QA-1, Section 2)

QUAL-4 Those Pu SPS systems, subsystems, and portions of subsystems required to perform an identified safety function are classified as (project) Quality Level 1 and will be constructed in accordance with applicable BNFL procedures for Quality Level 1 equipment.

(Quality Assurance Plan, Procedure QA-1, Section 2)

\section{E.13 Delivery Requirements}

TRANS-1 Care shall be taken to package components and subassemblies to ensure minimal breakage en route to the construction site. Electronic components and equipment shall be wrapped in shielded packaging to minimize failure due to static electricity encountered until installation. All items delivered to the Hanford Site are subject to receipt inspection; packaging shall be constructed to allow inspection without destruction of packaging components.

TRANS-2 Delivery methods shall be chosen to minimize cost while meeting required schedules.

SHIP-1 Items shall be prepared for delivery in accordance with the requirements of NQA-1, Subpart 2.2, "Quality Assurance Requirements for Packaging, Shipping, Receiving, Storage, and Handling of Items for Nuclear Power Plants." 
SHIP-2 All equipment will be crated in wood. Any loose items within the gloveboxes or subsystems will be secured. All equipment will be suitably protected from exposure to the natural environment.

SHIP-3 All penetrations and openings in gloveboxes shall be sealed to protect the opening and sealing surfaces.

SHIP-4 Sealing tape in direct contact with stainless steel shall have a chloride content of less than $50 \mathrm{ppm}$.

END OF APPENDIX B 